

\title{
Muddying the waters: Who Induces Volatility in an Emerging Market?
}

November, 2018

\author{
Paula A. Yepes-Henao \\ Universidad EAFIT \\ pyepesh@eafit.edu.co
}

Diego A. Agudelo*

Universidad EAFIT

dagudelo@eafit.edu.co

Ramazan Gencay

Simon Fraser University

rgencay@sfu.ca

All authors: Finance department. Universidad EAFIT. Carrera 49 No. 7 Sur 50. Medellín, Colombia. Phone (574) 2619500. *: Corresponding Author.

This article originated from a thesis completed by the first author in partial fulfillment for the degree of Master Sc. on Finance at Universidad EAFIT under the guidance of the second author. We acknowledge useful suggestions from Gustavo Canavire, Andres Ramirez, and Diego Restrepo from Universidad EAFIT and Carlos Castro from Universidad del Rosario. We are also grateful to Adriana Cárdenas, from Bolsa de Valores de Colombia (Colombian Stock Exchange) for providing the data, and David Arango and Camilo Silva for collecting the intraday database. All errors remain our own responsibility. 


\section{Muddying the waters: Who Induces Volatility in an Emerging Market?}

Do all investor types contribute equally to volatility formation? Although stock volatility should ideally originate only from fundamental innovations, it is embedded into prices through the trading process. We compare the relative contributions of trading by local institutions, local individuals and foreign institutions to the volatility of individual stocks, using a proprietary dataset and a battery of robust measures. Overall, neither local nor foreign institutions are the major drivers of volatility, not even during times of financial stress. Individuals consistently appear to induce more of the volatility and liquidity, behaving as the archetypical noise traders but also as liquidity providers.

Keywords: Emerging markets; stock volatility; intraday volatility measure; noise trading; foreign investors; retail investors

JEL codes: F30, G12, G15 


\section{Introduction}

Volatility is a primary concern for both investors and regulators in financial markets. Excessive volatility distorts economic decisions, impairs the credibility of prices as economic signals and reduces real investment by increasing the cost of capital ${ }^{1}$. In turn, regulators use volatility as an indicator of market quality. Volatility peaks may affect the proper functioning of markets, leading to a loss in investor confidence ${ }^{2}$. To understand how volatility is generated, theoretical models that predict a positive contemporaneous relation between trading activity and volatility are a starting point. First, from a market microstructure point of view, the arrival of new information encourages both trading and price variability (Easley and O'Hara, 1987; Barclay and Warner, 1993). Second, both informed and uninformed investors prefer to trade when the trading activity is high, inducing volatility increases (Kyle, 1985; Admati and Pfleiderer, 1988). It is also important to distinguish between two types of volatility (De Long, Shleifer, Summers, and Waldmann, 1989; Bandi and Russell, 2006; Harris, 2003). Fundamental volatility comes from the change in economic determinants of the stock value. In contrast, transitory volatility derives from the trading process itself and the liquidity demands of traders. This volatility is of particular interest for the exchanges and regulators since it depends on the market design. Nevertheless, we lack a deeper understanding of how trading activity drives volatility in spite of the well-known positive relation between the two (Karpoff, 1987; Schwert, 1989; Griffin, Nardari, and Stulz, 2005). In this context, this study explores how the trading by different types of investors contributes to volatility in an emerging market.

\footnotetext{
${ }^{1}$ See, for example, David (1997); Galeotti and Schiantarelli, (1994); Kupiec (1991); Shiller (2003).

${ }^{2}$ This point has been argued by Ozenbas, Schwartz, and Wood (2002); Pagano and Schwartz (2003); and Poon and Granger (2003).
} 
This is an interesting subject to study for several reasons. First, the reported heterogeneities between investor groups suggest that different groups have dissimilar roles in the trading process and perhaps distinct effects on volatility ${ }^{3}$. Moreover, the differential effects on volatility reported in previous studies are somewhat ambiguous and not necessarily comparable ${ }^{4}$. Second, we contribute to a better understanding of the trade-offs emergent in financial markets, with clear implications for stock exchanges, market regulators, and sell-side institutions. A case in point is the evidence that local individuals are the main liquidity providers in some emerging markets but that they lag behind other groups in terms of performance ${ }^{5}$. In addition, despite its contribution to liquidity, noise trading can also impose a welfare cost on the economy by reducing the capital stock and consumption (De Long et al, 1989). A third example is the discussion of the pros and cons of allowing foreign investors to trade freely in emerging markets ${ }^{6}$.

In this study, we compare the relative effect of trading by local institutions, local individuals and foreigners (all institutions) on the volatility in the Colombian stock exchange, Bolsa de Valores de Colombia (henceforth BVC), by taking advantage of two unique databases. First, from the

\footnotetext{
${ }^{3}$ Previous studies have reported that different investors groups have different degrees of information (Coval and Moskowitz, 1999; Grinblatt and Keloharju, 2000; Huang and Shiu, 2009), investment styles (Barber, Lee, Liu, and Odean, 2008; Grinblatt, Titman, and Wermers, 1995; Kaniel, Saar, and Titman, 2008), and behavioral biases (Malmendier and Shanthikumar, 2007).

${ }^{4}$ For example, whereas Holmes and Wong (2001) and Hamao and Mei (2001) find a stabilizing effect of foreign trading in four Asian stock markets, the results of and Wang (2007) portray them as volatility drivers in Japan and Indonesia and Thailand, respectively. There is also ambiguity with respect to the effect of individual investors. Kaniel, Saar, and Titman (2008) argue that individual investors can be characterized as the archetypical "noise trader" (De Long, Shleifer, Summers, and Waldmann, 1990; Kyle, 1985) but find no significant volatility increase after intense individual trading in NYSE. The following two studies in the Chinese stock markets, based on ownership rather than trading data also render ambiguous results. $\mathrm{Ng}$ and $\mathrm{Wu}$ (2007) report that the net buying of stocks by wealthy individual investors in China helps to reduce stock market volatility. Chen, $\mathrm{Du}, \mathrm{Li}$, and Ouyang (2013) find that foreign institution's ownership increases (reduces) volatility but foreign individual's reduce it. They also find positive relationships between all type of local ownership ( institutions, individuals and government) on stock volatility.

${ }^{5}$ In particular, Lee, Lin, and Liu (1999) and AUTHOR (2018b) in Taiwan and Colombia, respectively, identify individual investors as liquidity providers through passive orders and responsible for a larger share of the trading volume, with their performance lagging behind that of foreigners and local institutions.

${ }^{6}$ In this respect, Montiel and Reinhart (1999) and Chinn and Ito (2006) discuss the role of capital controls and foreign flows in Latin American and Asian emerging countries, respectively. Moreover, capital controls is a disputed point, backed by the results of studies such as Wang (2007) but not by those of Bekaert and Harvey (2003) and Lin, Lee, and Chiu (2009).
} 
BVC, we use a proprietary database of nine years that includes the number of trades, volume and value traded for both buys and sells of each of the three groups at the stock-day level. These data overcome the limitations of previous studies to properly identify the investor groups ${ }^{7}$. Second, we estimate intraday volatility and liquidity measures using a hand-collected two-year sample of trade and quote from Bloomberg and merge it with the previous database ${ }^{8}$. Using different panel data specifications and alternative measures, we test for the relation between the trading activity of each group and the volatility at the stock level. Thus, we are able to identify the type of investor inducing more volatility.

The contribution of this study to the literature is threefold. First, we compare the effect of the three types of investors in the same study, namely, foreigners, locals, and individuals on volatility, and not just two types as in previous studies. This is particularly important since foreigners are mostly institutions in emerging markets, whereas the local group includes both institutional and individual investors ${ }^{9}$. Lumping together the two local groups might obscure their effects on volatility. In our sample for Colombia, individuals represent $36 \%$ of traded value, local institutions represent $56 \%$, and the remaining $12 \%$ belongs to foreigners, all of them institutions ${ }^{10}$. Second, we measure the fundamental and transitory components of intraday volatility separately and

\footnotetext{
${ }^{7}$ This database allows us to overcome the limitations of previous studies on trading by different groups and volatility. Hamao and Mei (2001) use data on buys and sells for different types of investors in Japan but only at monthly frequency, and their foreign group contains both institutions and individuals. Wang (2007) acknowledges that his data on the Jakarta stock exchange do not discriminate between the two groups of local investors and that the data from the Thai Stock Exchange lack the number of operations.

${ }^{8}$ Since Bloomberg only stores 6 months of trade and quote data, data from this database were collected for only a twoyear period.

${ }_{9}^{9}$ From the BVC and two large brokerage houses, we confirm that the foreign group in Colombia is composed exclusively of institutions and no retail traders, including mostly international asset managers and mutual funds, with a minor share for hedge funds and direct investment.

${ }^{10}$ Moreover, individuals represent a larger share of the total trading in emerging markets than in developed markets. For instance, in the Chinese market, domestic individuals are responsible for up to $94 \%$ of trading value $\mathrm{Ng}$ and $\mathrm{Wu}$, 2007); likewise, they represent $90 \%$ in Taiwan (Barber et al., 2009) and approximately 60-75\% in Korea (Choe, Kho, and Stulz, 2005). In contrast, Kaniel, Saar, and Titman (2008) report for the US that only approximately $4 \%$ of the trading activity corresponds to individual investors.
} 
estimate the differential effects of the three groups on both measures. This allows us to determine the effects on volatility coming from market microstructural effects, such as the bid-ask bounce and the quote depth ${ }^{11}$.

A final contribution comes from the data itself. The Colombian stock market is an ideal market to study the effects of trading in volatility, at least for three reasons. First, these effects are arguably larger in small, less mature emerging markets like Colombia, and more critical to their development. This country is representative of emerging or frontier markets in early stages of development, unlike Korea and Taiwan that hold larger and more sophisticated markets, where the effects of different investor groups on the stability of markets have been studied the most (e.g Choe, Ko and Stulz, 2005; Choi and Choi, 2008) ${ }^{12}$. In addition, the data on the local institutional group available in Colombia is further identified as brokerage houses, pension funds, mutual funds, insurance companies, family offices and financial intermediaries, so we can examine the differential effects of different subgroups of these institutions. Finally, to our knowledge, this is the first study of its type conducted in a Latin American market. Since most of the previous studies use data from Asian stock markets, the Colombian stock market provides an out-of-sample test of their results.

The main findings can be summarized as follows. First, trading by local individual investors is the major driver of volatility, with a somewhat larger effect for sells than for buys. In turn, trades by local and foreign institutions have a lower impact on volatility, consequent with a stabilizing

\footnotetext{
${ }^{11}$ The importance of controlling for liquidity effects is illustrated by Kavajecz and Odders-White (2001). They assert that larger bid-ask spreads may have contrary effects on volatility: first, a mitigating effect by discouraging trading activity and second, an increasing effect due to a larger bid-ask bounce. Moreover, the same authors argue that a low quote depth also induces more volatility by increasing the frequency of trades outside the quotes.

12 To illustrate this point note that both Korea and Taiwan are among the five largest emerging markets by market capitalization (WFE 2016). By the same criteria, Colombia is in the lower quartile. Furthermore, FTSE (2017) classifies Korea and Taiwan as developed and advanced emerging markets, respectively, while Colombia is grouped among the secondary emerging markets.
} 
role of institutions in the market ${ }^{13}$. These results are robust for different subsamples of the data, alternative specifications, and various measures of intraday volatility. Moreover, contrary to what is suggested by the foreign flows literature, the effect of foreign trading on volatility is significantly lower than the effect of both local groups, even in times of worldwide financial stress. In addition, we find that the trading by short-term local institutions (e.g., brokerage houses) has a larger effect on volatility than that of long-term firms (e.g., funds).

Moreover, the results on intraday measures confirm that individual investors, as a group, have the largest impact on fundamental volatility but at the same time the largest contribution to liquidity. This is consistent with a dual role: while some of these investors provide liquidity using passive orders, others behave as active speculators, inducing volatility. This dual role of individuals has precedents in the literature. For example, Barber and Odean (2001) conjecture that a group of day traders contributes to liquidity trough passive orders, whereas another group might be creating volatility with an aggressive trading style. Additionally, Foucault, Sraer, and Thesmar (2011) report that retail trading increases volatility in the Paris Bourse ${ }^{14}$. We obtain confirmatory evidence by comparing the cost of execution and daily performance of the three types. We find that although individuals have a relatively low average cost of execution, they present the worst average daily performance of the three groups; thus, this group is not dominated by informed traders. This is consistent, with retail investors behaving, as a group, as the archetypal noise trader

\footnotetext{
${ }^{13}$ Arguably, "smart-money" investors should stabilize prices by arbitraging away mispricing (Black, 1986; De Long et al., 1990). This stabilizing role has been reported for pension funds in the US by Lakonishok, Shleifer, and Vishny (1992) and for institutions in China ( $\mathrm{Ng}$ and $\mathrm{Wu}, 2007)$. However, the evidence here goes against the theoretical model of Gabaix, Gopikrishnan, Plerou, and Stanlety (2006) that implies that large institutions' trading in low liquidity markets should induce volatility.

${ }^{14}$ Furthermore, the liquidity providing role of individual investors has also been reported in Taiwan by Lee, Lin, and Liu (1999), in France by Barrot, Kaniel and Sraer (2016) and in Australia by Tian, Do, Doung and Kaley (2015). Evidence of their aggressive trading around news has been reported in Taiwan by Tsai (2004), in the US by Barber and Odean (2007) and Kaniel, Liu, Saar and Titman (2012) and in Australia by Tian, Do, Doung and Kaley (2015). Finally, Lee et al (1999) report that in Taiwan, large retail traders behave as informed investors, whereas small ones are liquidity providers.
} 
in the sense of Black (1986), Kyle (1985) and De Long, Shleifer, Summers, and Waldman $(1989,1990)$.

To our knowledge, the study most related to ours is Wang's (2007) who test for the effects of daily foreign flows in the volatility of Indonesian and Thai stock markets. He finds that foreign sells increase market volatility, and fails to find any effect from local trades. Our study differentiates in at least two aspects: First, we separate the effect of the two main local groups: institutional and locals. As demonstrated by previous studies in emerging markets the local group is far from homogeneous. Local institutions tend to be more sophisticated investors than retail traders, with larger trades, superior trading execution, and better performance in different time horizons (Barber et al, 2008 in Taiwan; Agudelo, Byder, Yepes-Henao, 2019 in Colombia). Second, by using a trade and quote database for Colombian stocks, we are able to account for the market microstructural effects underlying volatility increases, such as the bid-ask bounce (Roll, 1984), and the quote depth. As argued by Kavajecz \& Odders-White (2001), market microstructure effects are critical for volatility formation (see footnote 11).

All in all, our results highlight the importance of the interaction between different groups of traders in a stock exchange in the processes of price formation and liquidity providing, with volatility as a side effect. For an emerging market, we identify the central role of individual investors as the main liquidity providers but also as the ones "muddying the waters" with their aggressive trades. In contrast, local institutions clearly behave as more sophisticated investors, taking advantage of the liquidity provision, inducing relatively less volatility, and obtaining a better overall performance. 
The remainder of this article is organized as follows: section 2 outlines the hypotheses; section 3 describes the databases; section 4 explains the methodology; section 5 presents and discusses the results, and section 6 concludes.

\section{Hypotheses}

The direct relation between trading and volatility is the natural starting point to formulate the hypotheses of this study. This has been extensively studied, as summarized by the survey paper of Karpoff (1987). He explains that the positive relation between trading and volatility comes from "the rate of information flow to the market, how the information is disseminated, the extent to which market prices convey the information, the size of the market, and the existence of short sales constraints" (Karpoff, 1987, p.109). Besides, Kaul and Lipson (1994) find that for NASDAQ stocks, the number of trades is the relevant measure of the market activity effect on volatility, rather than the size of trades, which does not convey information. However, Chan and Fong (2000), with a sample that also includes NYSE stocks, report that the size of trades does have a role in explaining higher volatility.

In turn, theoretical models in market microstructure predict a positive contemporaneous relation between trading activity and volatility. First, the arrival of new information encourages both speculative trades and price variability, as in the model of Easley and O'Hara (1987). Second, both informed and liquidity investors prefer to trade when the trading activity is high (Admati and Pfleiderer, 1988), which explains coincident clusters of volume and volatility. In turn, some evidence shows that trading activity generates volatility by itself aside from fundamentals. For example, French and Roll (1986) show that volatility is higher whenever exchanges are open. 
In this context, we are interested in contrasting the effects of trading by different groups of investors on stock market volatility. Based on the theoretical models and the extant empirical evidence, we formulate the following three hypotheses:

H1. Trading by individuals increases the volatility at the stock level

As a group, individual traders are considered the quintessential noise trader (Kaniel et al. 2008). Since noise traders trade randomly, their increasing trading should induce volatility (De Long et al, 1989). Evidence in support of the informational disadvantage of retail investors has been presented in Colombia by Agudelo et al (2019) and in Taiwan by Lee, Liu, Roll, and Subrahmanyam (2004) and Barber et al (2008) ${ }^{15}$. Day trading can be seen as an extreme example of uninformed trading by individuals, attributed to overconfidence (Barber and Odean, 2004). In turn, Venezia, Nashikkar and Shapira (2011), using trading data of Israeli stocks, report that herding among amateurs Granger-cause volatility. In a related point, Campbell, Lettau, Malkiel, and $\mathrm{Xu}$ (2001) conjecture that day trading by small investors explains higher idiosyncratic volatility for US stocks over time. In the same vein, Kyröläinen (2008) reports evidence that daytrading by individuals is associated with intraday volatility in the Finnish stock exchange ${ }^{16}$. Finally, Choi and Choi (2008) find evidence consistent with individuals generating systematic noise in Korea.

In turn, individual traders have also been identified as important liquidity providers in the US (Kaniel et al, 2008; Barber and Odean, 2001), France (Barrot et al, 2016), Australia (Tian et al.,

\footnotetext{
${ }^{15}$ This does not rule out the possibility that a group of individuals can be successful short-term speculators, for example, around corporate news, as documented by Kaniel et al. (2012) for the US, and Tsai (2014) for Taiwan. ${ }^{16}$ On the contrary, $\mathrm{Ng}$ and $\mathrm{Wu}(2007)$ report that net buys by wealthy individual investors contribute to reducing stock volatility in China, and Wang (2007) fails to find any relation between individual trading activity and volatility for the Thai stock market.
} 
2015), Taiwan (Lee et al., 1999; Lee et al, 2004) and Colombia (Agudelo et al, 2019). This liquidity provision might modify the volatility effect of individual noise trading. This serves as an additional justification for controlling for liquidity effects when testing the effects of individuals on volatility and vice versa.

H2. Trading by institutional investors induces less volatility than does trading by individuals. In the theoretical models of Kyle (1985) and Glosten and Milgrom (1985), informed investors drive prices close to their fundamental values, taking advantage of the mispricing created by noise traders Therefore, informed traders can be expected to mitigate transitory volatility. Previous studies have found that the performance of institutional investors is superior to that of retail investors in Taiwan (Lee et al 2004) and Colombia (Agudelo et al, 2019), and both studies link this performance to superior information. Therefore, we expect that institutional trading has a lower effect on volatility than individuals' trading.

Little evidence has been presented on the contribution of institutional investors to stock volatility. Kyröläinen (2008) and Hamao and Mei (2001) fail to find any relation between institutional investors and stock volatility in Finland and Japan, respectively. Only $\mathrm{Ng}$ and $\mathrm{Wu}$ (2007) find that net institutional sells have a mitigating effect in the Chinese stock market. One reason for this might be the difficulty in distinguishing among the trades by different types of institutions. Different firms should have different styles of trading and diverse degrees of information. As two opposite examples, we might find a value investor with a long-term orientation, and a short-term institutional speculator, whose behavior might be closer to that of an individual day trader. Our data allow us to mitigate this limitation. In the last set of results, we classify local institutions into two subgroups: short-term (e.g., brokerage houses) and long-term 
investors (e.g., pension funds). We expect a lower effect on volatility by the trading activity of the latter, since they should be more patient investors, use more passive orders, and be better suited to trade on mispricing opportunities. In contrast, we expect that short-term institutions are more aggressive and speculative in their trades and therefore have a larger effect on volatility.

H3. Trading by foreigners induces less volatility than trading by individuals. The expected effect of foreign investors on volatility is less clear than of the other two groups. There are arguments and evidence to support contrary expectations, as explained below. Given these two opposite expectations on the effect of foreigners on volatility, we let the data to speak for itself.

On the one hand, there is evidence that foreign flows, especially when selling in rush, can create excess volatility in a set of 45 emerging markets at market level (Bae, Chan and $\mathrm{Ng}$, 2004). Wang (2007) reports that foreign selling increases the volatility of the Indonesian and Thai equity markets. He argues that foreigners' effect on volatility is made worse by the leverage effect and the reduction of the investor base. This volatility generation might also be related to the evidence that sudden portfolio rebalances of foreign investors, prompted by negative international factors, can lead to large capital outflows and drops in emerging market returns (Griffin, Nardari, and Stulz 2004; Richards, 2005). In this respect, we also examine the effects of foreign flows on volatility in days of worldwide financial stress (peaks in the VIX indicator), when presumably those consequences should be larger. Moreover, due to the link between lower liquidity and higher volatility, discussed above, a more liquidity-demanding trading style can also play a role. In this sense, studies in emerging markets such as Korea (Choe et al. 2005), Taiwan (Lee et al.2004) and 
Colombia (Agudelo et al, 2019) report that foreign investors are more aggressive investors, demand liquidity through active orders, and trade with larger execution costs.

On the other hand, we find at least two arguments against foreigners inducing volatility. First, foreign investors in Colombia, as in many other emerging markets, are almost exclusively institutions ${ }^{17}$. Thus, the argument presented in $\mathrm{H} 2$ above can also apply to them, and foreign trading might have a lower effect on volatility than trading by individuals. Along these lines, Holmes and Wong (2001) report that the liberalization processes reduced the asymmetric response of volatility in Southeast Asian stock markets and increased the flow of informed traders. Moreover, Lin, Lee, and Chiu (2009) find a stabilizing effect of foreigners in a post-liberalization era in Taiwan, after the government lifted restrictions on foreign ownership. Second, when not differentiating between local groups of investors as in Wang (2007) for Indonesia, foreign net flows might be just proxying for undetected net selling coming from a specific group of local investors (e.g. retail traders), that might be the main driver of volatility. Thus, the finding of the previous literature of a positive relationship between foreign sales and volatility in some emerging markets is not necessarily conclusive.

\section{Data}

We use two main datasets. First, we use a proprietary database from the Colombia Stock Exchange (BVC) from January 1, 2007 to January 29, 2016 on trading activity by type of investor. This database includes the following three measures of activity on a stock-day basis by investor group: number of trades, traded value (in local currency units) and traded volume (number of stocks), for

\footnotetext{
${ }^{17}$ Foreign investors in the Colombian stock market are exclusively institutions, with no individuals, and mostly include international asset managers and mutual funds as well as a few hedge funds and some foreign direct investment. This is anecdotally confirmed by the BVC and one of the main Colombian Brokerage houses.
} 
both buys and sells. As in similar studies in emerging markets (Lee et al, 2004; Choe et al, 2005; Barber et al, 2008), this database identifies three main groups of investors: local individuals, foreigners, and local institutions. In the latter group, a further classification is provided in brokerage firms, pension funds, family offices, mutual funds, trusts, corporations, and banks and other financial institutions. To identify the parties involved in each trade, the BVC uses a unique tax identification number (NIT). However, for privacy reasons, the database reports daily information summarized by investor group; hence, we cannot identify or track the trades of any particular investor.

To clean up this database, we validate that the stocks bought and sold in each day are consistent according to the three measures, finding minimum imbalances in the records. In addition, we take into account adjustment factors to correct for splits. Moreover, we omit the trading activity of investors classified as "ADRs" (American Depository Receipts), since we cannot tell which group of investors owns such transactions, which are performed by brokerage firms on behalf of ADR investors. Those trades make up approximately $4,75 \%$ of the overall trading value on the stock exchange. Finally, we complete this database with the daily high, low, opening and closing prices from Bloomberg.

Second, to account for market microstructural effects on volatility, we use a hand-collected intraday database from Bloomberg, which encompasses trades and quotes for the 42 most traded Colombian stocks. Specifically, it includes data on price and volume for transactions and tick-bytick data on price and depth for quotes (bid and ask), from August 23, 2010 to August 31, 2012. The Colombian stock market operates most of the time as a continuous order-driven market, but it switches to a call auction at the closing (last five minutes) and after large price changes (called "volatility call auctions"), as described by Agudelo, Gutierrez and Múnera (2014). Since we are 
only interested in the intraday volatility associated with the continuous market, we omit the data belonging to both types of call auction.

\section{Methodology}

\subsection{Daily volatility model}

Daily stock volatility is usually estimated using ARCH-GARCH and/or stochastic volatility models. Nevertheless, ex post measures suggest that the volatility estimations of the first group do not explain the variability in ex post returns (Andersen and Bollerslev, 1998). In turn, the second group provides inefficient estimators that contain highly non-Gaussian measurement errors, leading to wrong statistical inference (Alizadeh, Brandt and Diebold., 2002). Thus, in this study, we use a simple measure of daily volatility-based intraday ranges, with properties of efficiency and consistency well backed up by the specialized literature (Alizadeh et al., 2002; Andersen and Bollerslev, 1998; Yang and Zhang, 2000). Volatility range-based measures have been used by related studies such as Wang (2007) and Chiang and Wang (2011). Specifically, the log range measure is the logarithmic difference between the high and low prices in a day:

$$
\sigma_{i, t}=\ln \left(\text { High_price }_{i, t}\right)-\ln \left(\text { Low }_{\text {price }_{i, t}}\right)
$$

We measure the effect of both domestic groups and foreigners on stock volatility [1] by estimating the following panel data regression of the log of volatility against trading activity variables. Similar specifications are by Wang (2007) and Kyröläinen (2008).

$$
\ln \left(\sigma_{i, t}\right)=X_{i j, t}^{\prime} \beta+\sum_{l=1}^{L} \beta_{l} \ln \left(\sigma_{i, t-l}\right)+\sum_{k=1}^{4} \beta_{k} D_{k}+\left\{\sum_{j=1}^{3} \beta_{j} \ln \left(1+V_{i, j, t}\right)\right\}+\varepsilon_{t}
$$


where $\sigma_{i t}$ is the stock price volatility. $X_{i j, t}^{\prime}$ indicates macro and stock control variables ${ }^{18}$, namely, systematic volatility and foreign exchange rate volatility, contemporaneous and one-lag daily stock returns; $D_{k}$ corresponds to a dummy variable for day of the week (excluding weekends) ${ }^{19} ; j$ is the type of investor (foreign, institutional, and individual). The variable of interest, $V_{i, j, t}$, represents the trading activity variable by each type of investor, initially measured as total traded value. Finally, volatility lags account for the well-known persistence of volatility (Kyröläinen, 2008).

\subsection{Intraday volatility models}

Taking advantage of the intraday trading database described above, we are able to decompose volatility into two components: fundamental and transitory (Harris, 2003). Fundamental volatility refers to price variations due to changes in fundamental factors that alter the stock economic value. On the other hand, transitory volatility is unrelated to fundamentals and comes from the trading activity itself and microstructural effects, for example, the bid-ask bounce of trading prices (Roll, 1984) and the post-trade price reversal (Huang and Stoll, 1996). In this respect, in a simple model following the spirit of Roll (1984) and Bandi and Russell (2006), total volatility [1] can be approximately decomposed as the sum of the log of mid-price volatility, the measure of

\footnotetext{
${ }^{18}$ As macro control variables, we included the main stock market index (COLCAP) and foreign exchange rate volatilities. Both volatilities are measured as in Equation [1]. We control for systematic volatility, a well-known determinant of the total stock volatility (Campbell et al., 2001). In turn, controlling for the volatility of the exchange rate takes care of effects on stock valuation coming from the unhedged exposition to foreign exchange risk at the firm level. Moreover, by including macro-level factors, we control for any effect of total net buys on market-wide volatility that might drive the results at the stock level. As alternative macro control variables, we also try the VIX index, the volatility of the S\&P500 index, the TED spread and dummies for days of macroeconomic events, but adding them only increases the R-square by less than $1 \%$.

${ }^{19}$ Kyröläinen (2008) notes that Mondays may involve greater volatility than other trading days due to information events that occurred over the weekend.
} 
fundamental volatility, and the log of the bid-ask spread, proxy of the transitory volatility ${ }^{20}$. Thus, an alternative specification for equation [2] is:

$$
\ln \left(\sigma_{m p_{i, t}}\right)=X_{i j, t}^{\prime} \beta+\sum_{l=1}^{L} \beta_{l} \ln \left(\sigma_{m p_{i, t-l}}\right)+\text { Spread }_{i, t}+\sum_{k=1}^{4} \beta_{k} D_{k}+\quad\left\{\sum_{j=1}^{3} \beta_{j} \ln \left(1+V_{i, j, t}\right)\right\}+\varepsilon_{t}
$$

where $\sigma_{m p_{i, t}}$, the mid-price volatility, is calculated as the daily average of log range measures [1], estimated in five-minute intervals. The bid-ask spread, Spread $_{i, t}$, can be alternatively measured as the daily average of the quoted or the effective bid-ask spread, both estimated from transaction and quote data. The quoted spread is computed as the daily average of differences between the ask and bid prices scaled by the mid-price and measured at five-minute intervals $(t k)$, as follows.

$$
\text { Quoted_Spread }{ }_{i, t}=\text { mean }\left(\frac{a s k_{i, t k}-b i d_{i, t k}}{\text { mid_price }_{i, t k}}\right)
$$

The effective spread is defined as twice the absolute value of the logarithm of the trade price relative to the mid-price averaged for each stock-day, where $\tau$ is a given transaction in the day:

$$
\text { Effective_Spread }_{i, t}=\text { mean }\left|2 * \ln \left(\frac{\text { trade_price }_{i, \tau}}{\text { mid_price }_{i, \tau}}\right)\right|
$$

The quoted spread measures the potential cost of buying or selling in trades smaller than the ask or bid depth, respectively. In turn, the effective spread reflects the difference between the effective cost at which investors trade relative to the mid-price (Goyenko, Holden, and Trzcinka,

\footnotetext{
${ }^{20}$ Assuming, first, that trades happen randomly at the bid or ask prices, and, second, that there exists a constant proportional bid-ask spread, it is easy to show that starting from [1], High_price $e_{i, t}=$ High_midprice $_{i, t} *$ $\left(1+\right.$ Spread $\left._{i, t}\right)$ and Low_price $_{i, t}=$ Low_midprice $_{i, t} *\left(1-\right.$ Spread $\left._{i, t}\right)$, we can decompose total volatility into its fundamental and transitory components: $\ln \left(\sigma_{i, t}\right) \approx \sigma_{m p i, t}+\ln \left(1+\right.$ Spread $\left._{i, t}\right)$.
} 
2009). This measure accounts for the fact that some trades occur inside the quoted spread and that large trades have a price impact.

To test the relation between transitory volatility and investors' trading activity, we regress both measures of the bid-ask spread against trading activity and its determinants as follows:

$$
\text { Spread }_{i, t}=\sum_{l=1}^{L} \beta_{l} \ln \left(\sigma_{i, t-1}\right)+r_{i, t}+\text { log_price }_{i, t}+\sum_{k=1}^{4} \beta_{k} D_{k}+\left\{\sum_{j=1}^{3} \beta_{j} \ln \left(1+V_{i, j, t}\right)\right\}+\varepsilon_{t}
$$

The extant literature (e.g., Grullon, Kanatas, and Weston, 2004; Hendershott and Molton, 2011) has identified the following determinants of the bid-ask spread: the stock return $r_{i, t}$, the stock volatility $\sigma_{i, t}$, and the stock price level $\log _{-}$price $_{i, t}$. Trading activity is also an important determinant of bid-ask spreads, but here, it is measured for each of the three types of investors: foreigners, local institutions and local individuals, $V_{i, j, t}$. We also include day dummies, $D_{k}$.

Partially based on Grullon et al., (2004), we use an alternative measure of liquidity, the daily averaged quote depth. We define it as the average intraday quoted depth at the bid and ask prices in each quote update. Similar to [6], the model with this liquidity measure is the following:

$$
\log \left(\text { Depth }_{i, t}\right)=\sum_{l=1}^{L} \beta_{l} \ln \left(\sigma_{i, t-1}\right)+r_{i, t}+\text { log_price }_{i, t}+\sum_{k=1}^{4} \beta_{k} D_{k}+\left\{\sum_{j=1}^{3} \beta_{j} \ln \left(1+V_{i, j, t}\right)\right\}+\varepsilon_{t}
$$

We overcome three possible complications in our econometric estimation. First, the two components of trading activity, the average size of the trades and the number of transactions, might have different effects on the alternative measures of volatility and liquidity presented above. In response, we run alternative specifications of models [2], [3], [6] and [7], substituting the log of 
the total traded value by the type of investor, with the logs of the number of trades and the average trading value ${ }^{21}$.

Second, the previous literature asserts a bi-directional relation between volatility and the bidask spread. One might expect that a higher bid-ask spread leads to a larger bid-ask bounce that in turns contributes to a higher volatility (Roll, 1984). In addition, higher volatility induces larger bid-ask spreads in the theoretical model of Kyle (1985). To manage this potential endogeneity, we perform 2-stage least squares regressions to estimate models [3], [6] and [7], using instruments for the volatility, spread and quoted depth, respectively.

Finally, since our data have a large $T$ dimension, potential cross-sectional and autocorrelation of errors are expected. In response, we run the panel data models using Driscoll and Kraay's covariance matrix estimator (Driscoll and Kraay, 1998), which provides a heteroskedasticity- and autocorrelation-consistent covariance matrix (Hoechle, 2007). This approach is consistent independently of the panel's cross-sectional and temporal dimensions.

\subsection{Alternative measures of intraday volatility}

As a robustness test, we estimate three alternatives measures of fundamental volatility that mitigate the inherent microstructural noise from high-frequency data ${ }^{22}$. First, we employ the bipower variation estimator proposed by Barndorff-Nielsen and Shephard (2004) as being robust to finite jumps. The estimator is calculated from the cumulative sum of the products of adjacent absolute returns from trading prices, sampled at five-minute intervals $(t k)$, as follows:

\footnotetext{
${ }^{21}$ Since $A v g_{-} t r a d e d_{-} v a l u e_{i, t, k}=$ traded_value $_{i, t, k} / N_{-} o p_{i, t, k}$, taking logs, we have a linear decomposition of trading activity: $\ln \left(\right.$ traded_value $\left._{i, t, k}\right)=\ln \left(\right.$ Avg_traded_value $\left._{i, t, k}\right)+\ln \left(N_{-} o p_{i, t k}\right)$

${ }^{22} \mathrm{We}$ thank an anonymous referee for suggesting these additional measures.
} 


$$
B V_{i, t}=\frac{\pi}{2} \sum_{t k=3}^{n}\left|\ln P_{i, t k}-\ln P_{i, t k-1}\right|\left|\ln P_{i, t k-1}-\ln P_{i, t k-2}\right|
$$

Second, we estimate the two-scale realized volatility measure (TSRV), which is robust to trading frictions (such as bid-ask bounces), informational effects and measurement or data recording errors (misplaced prices), which are latent sources of noise (At-Sahalia, Mykland, and Zhang, 2011). Furthermore, the authors claim that in the presence of market microstructure noise, this measure mitigates the variance of the noise derived from too frequent sampling of prices (e.g., each second). The TRSV combines a fast and a slow time scale volatility measure, as follows:

$$
T R S V_{i, t}=\frac{1}{G} \sum_{g=1}^{G} r v^{g}(V, \delta)_{i, t}-\frac{n(\delta)_{g}}{n} r v\left(V, \delta_{f}\right)_{i, t}
$$

where $r v\left(V, \delta_{f}\right)_{t}$ is the realized volatility with the fast time scale estimated with prices sampled at $n$ intervals. In turn, $r v^{g}(V, \delta)_{t}$ represents the volatilities estimated with $G\left(=\delta / \delta_{f}\right)$ different samplings with the slow time scale, each one with prices sampled at $n(\delta)_{g}$ intervals $(=n / G)$. Each volatility is calculated as follows:

$$
\begin{aligned}
& r v^{g}(V, \delta)_{i, t}=\sum_{t k=2}^{n(\delta)_{g}}\left(\ln P_{i, t k}^{g}-\ln P_{i, t k-1}^{g}\right)^{2} \\
& r v\left(V, \delta_{f}\right)_{i, t}=\sum_{t k=2}^{n}\left(\ln P_{i, t k}^{f}-\ln P_{i, t k-1}^{f}\right)^{2}
\end{aligned}
$$

where $P_{i, t k}^{g}$ and $P_{i, t k}^{f}$ represent the trading prices sampled at the slow and fast time scales, respectively. For our analysis, we choose a sampling interval of 5 minutes $\left(\delta_{f}\right)$ for the fast sampling and 30 minutes $(\delta)$ for the slow one (Andersen, Bollerslev, Diebold and Labys, 2001; At-Sahalia et al., 2011).

The third and last alternative measure is the median realized volatility MedRV estimator proposed by Andersen, Dobrev, and Schaumburg, (2012). This measure is an improvement over 
the bipower variation estimator (Barndorff-Nielsen and Shephard (2004)) that corrects for a possible upward bias but preserves jump robustness. The authors argue that the new measure leads to better efficiency properties and is less susceptible to the presence of zero returns in the sample. $M e d R V$ is based on the median of three neighbor returns, as follows:

$$
M e d R V_{i, t}=\left.\frac{\pi}{6-4 \sqrt{3}+\pi}\left(\frac{n}{n-2}\right) * \sum_{t k=2}^{n-1} \operatorname{med}\left(\left|\Delta P_{i, t k},\right| \Delta P_{i, t k-1}|,| \Delta P_{i, t k-2} \mid\right)\right|^{2}
$$

\section{Results}

\section{$\underline{5.1 \text { Summary statistics }}$}

Table 1 presents the summary data for of the trading of each of the three groups of investors in the Colombia Stock Exchange, for the whole sample and for each of the four quartiles of market capitalization. Panel A displays the results for the daily average trade value in US dollars. Overall, local institutions are responsible for more than half of the total traded value in the whole sample, 3,5 and 1,5 times more than the value traded by foreigners and individuals, respectively. Local institutions are responsible for most of the trading in value in each of the top three quartiles of size, while in the lowest quartile, individual investors are the dominant group. Barber, Odean, \& Zhu (2008) also report that local individuals are the more active traders in small-cap stocks for the US market. In contrast, foreigners have the smallest share of the daily average trade value in the whole sample and in each of the four quartiles of size. Since trading activity, measured as traded value, depends on both of the number of trades and the average trade value, we examine both variables separately.

When we measure trading activity by number of trades, local institutions and individuals switch places, as shown in Panel B. The largest share belongs to local individuals, with 1,5 and 4,4 times 
more average trades than local institutions and foreigners, respectively. In turn, Panel C presents the results for average trade value, which is the largest for local institutions, followed by foreigners and individual investors. Barber et al., (2008), Choe et al., (2005) and Dvořák (2005) report similar results in those two variables in Taiwan, Korea and Indonesia, respectively. Overall, the results in Table 1 do not unambiguously suggest whose trading activity raises volatility the most. It may be institutions, with the largest trades and value traded, or individuals, with the most frequent trades.

The evolution of trading activity by the three groups can be appreciated in the plot of the share of trading (in dollar value) over the sampled time. We observe that whereas the share of trading of local institutions remains relatively constant, there are clear trends for the other two groups. After early 2009, individuals progressively make up a lower share of the total trading, whereas foreigners' share continues to grow. Moreover, in November of 2012, the debacle of the most important Colombian brokerage house, Interbolsa, due to a liquidity crisis caused by failed highly leveraged trades, is a factor that weakened the confidence of retail traders in the stock market (BVC, 2012).

In turn, Table 2 reports the summary statistics for the daily volatility of individual stocks and the market index. Average volatility is higher for the smallest firms, in line with the results of Chang and Fong (2000), for both NYSE and NASDAQ. Similarly, we obtain a somewhat higher volatility autocorrelation in the lowest quartile. The differences in the share of trading and volatility by firm size in Tables 1 and 2 and the varying composition of the trading in Figure 1 motivate us to conduct some of the analyses below separately by size quartiles and to split the sample period in half. In addition, the high autocorrelation in volatility requires the use of a panel data model with volatility lags, as explained in section 4.1. 


\subsection{Differential effects on stock volatility}

We estimate the effects of trading activity on volatility using the panel data model [2] at the stockday level. We present alternative specifications of this base model in Tables 3, 4 and 5. As explained above, in each case, we report the results for the whole sample, the two halves of the sample period, and each of the four size quartiles. Table 3 describes the results of regressing the daily stock volatility against the total traded value by type of investor. First, we note that the explanatory variables have the expected signs: stock volatility is positively related to the market and foreign exchange rate volatilities and to the three trading activity variables ${ }^{23}$. Most remarkably, the trading activity of individuals has the largest positive coefficient, a result that is robust in both subperiods and in each of the four size quartiles. Using Wald tests, we find that the trading value coefficients for individuals are statistically larger than those for the other two groups. This suggests that individuals are the main drivers of volatility, even in the period 2012-2016, when they fall to the last place in the overall share of trading (see Figure 1). This result agrees with the evidence for the Finnish market reported by Kyröläinen (2008) and for NYSE by Kaniel et al., (2008). It is also consistent with H1 that proposes that individual investors are the main inducers of volatility, as they mostly act as noise traders. However, further analysis is required to better understand this relation.

On the other hand, the trading of both foreign and local institutions also drives up volatility but to a lesser extent than the trading of individuals. For example, for the total sample, the coefficient for individual trading is 4 and 13 times larger than the coefficients for the trading of

\footnotetext{
${ }^{23}$ In omitted day-of-the-week effects, we find that Fridays tend to be more volatile in Colombia, unlike Kyröläinen (2008), who finds that Mondays tend to be more volatile.
} 
institutions and foreigners, respectively ${ }^{24}$. We interpret this lower effect on volatility as suggesting that both groups have a stabilizing role in stock volatility (H2 and H3). Similar findings have been reported by Black (1986) and De Long et al., (1990) for institutions and by Holmes \& Wong, (2001) and Lin et al., (2009) for foreigners.

To further explore these relations, we decompose the total traded value of each group into the number of trades and average trade value and replace it with these measures in model [2], as reported in Table 4 . The positive and highly significant coefficients of the number of trades for each type of investor and in each of the seven samples indicates that this variable is the key driver of volatility, consistent with the findings of Jones, et.al (1994) in NASDAQ. This effect is larger for individual's activity, supporting H1. In addition, as presented in the Wald tests, this effect is significantly different from the effect from either of the other two groups at the $1 \%$ level in almost all cases, supporting the stabilizing role of both institutions (H2 and $\mathrm{H} 3)$.

In contrast, the effect of the average trade value on volatility runs in the opposite direction. The coefficient for the average trade value is negative and statistically significant in six out of seven samples for foreigners. Similarly, local institutions' average trade value has negative impact on stock volatility, especially in the second period and in the two smaller size quartiles. This is consistent with the mitigating role of those two types, discussed in $\mathrm{H} 2$ and $\mathrm{H} 3$ : when controlling by number of trades, larger trades by professional investors are not disruptive of prices but, on the contrary, tend to reduce price variability. This corroborates the findings by Holmes and Wong (2001) and Lin et al., (2009) in East Asian stock markets. At the microstructural level, an anecdotal

\footnotetext{
${ }^{24}$ Notably, the large difference in the coefficients of foreign trading activity in the two subperiods increases fivefold from 0,0022 (2007-2011) to 0,0109 (2012-2016). This might be related to the increasing role of foreigners in the total trading activity of the stock market over time, as shown in Figure 1.
} 
explanation for this negative effect of large institutional trades on volatility is the general practice of cross-trading between large firms at the mid price, as well as trading in the closing call auction ${ }^{25}$.

We also explore the differential effects of buying and selling trading activity on volatility. Specifically, we replace the total traded value for each group by the traded values in buys and sells in model [2], as presented in Table $5{ }^{26}$. We observe that the effect of both types of trading for each of the three groups is positive in all 42 cases and statistically significant at the $1 \%$ level in all except two cases. In addition, when comparing the corresponding effect of buys (sells) of foreigners and local institutions with that of individual buys (sells), Wald tests indicate that the latter is always higher than the former, a difference that is statistically significant in all cases but one (one). This evidence provides additional support to the three hypotheses of this study.

The results also allow us to contrast the differential effects between sells and buys for the same type of investor. Table 5 shows that the coefficients for sells are larger than those for the respective buys for each of the three types of traders in the seven samples, with only three exceptions. In omitted Wald tests, we find that this difference is significant at the $10 \%$ level or lower for 11 out of 21 cases and that in no case is the effect of buys significantly larger than of sells. This evidence agrees with previous studies, such as Hamao and Wei (2001) for Japan and Wang (2007) for Thailand, that report such an asymmetric effect of sells over buys on volatility.

A final noteworthy result in Table 5 is that the coefficient of foreign sales is not larger than that corresponding to local individuals and institutions. This does not support the disruptive effect on volatility attributed to foreigners by Wang (2007) in two Asian markets. Aside from the fact that

\footnotetext{
${ }^{25}$ We thank Jairo J. Agudelo from Valores Bancolombia and Gregorio Toro at AdCap for this insight.

${ }^{26} \mathrm{~A}$ limitation of this analysis is that the available data do not differentiate between active and passive buys (sells) by type of investor. According to the studies on limit order markets, active sells and/or buys are the ones that should change prices and have a definite effect on volatility (Chang and Fong, 2000).
} 
both studies use data well before ours (up to 1999), this difference could be attributed to the fact that the first study uses data at the country-month level and that neither of them observes the trading activity of the other two types of investors ${ }^{27}$. Moreover, our result is consistent with the results from Holmes and Wong (2001) and Lin, Lee, and Chiu (2009) on the effect of market liberalization measures in East Asian markets. In any case, we test below for the robustness of this finding with alternative specifications and focus on times of crisis.

\section{$\underline{5.3 \text { Differential effects on stock market volatility with intraday data }}$}

In this section, we study the effects of trading by the three groups in intraday data on volatility and liquidity measures calculated from the trade and quote sample described in section 3 . This will serve as a robustness test of the results in the previous section and will provide additional insight on the microstructural factors driving the volatility-volume relation. These four measures are estimated with intraday data for a sample of two years. We estimate both the total daily (transitory) volatility and the mid-price (fundamental) volatility with the daily average of log range measure [1] applied to transaction prices and mid-prices, respectively. The effective bid-ask spread is estimated by trade as [5] and daily averaged. The depth measure is the daily average of the depths at the bid and the ask in each updated quote. Table 6 summarizes the effects of investor trading activity on the total and fundamental volatilities according to model [3] and the two measures of liquidity, namely, bid-ask spread and quoted depth, according to models [4] and [5], respectively.

\footnotetext{
${ }^{27}$ For example, assuming that individuals are the main drivers of volatility and observing only foreign net sells in times of high volatility, missing data on the trades of the other two groups, one would wrongly infer that foreign outflows are inducing volatility.
} 
We first examine the results of transitory volatility in column (1). They are qualitatively the same as the results in Table 1: trading by each of the three groups induces volatility. This effect is significantly larger for individuals than for local institutions, whose effect in turn is larger than that of foreigners. Since we control for liquidity with an instrument of the bid-ask spread, the increasing volatility is not explained in principle by microstructural effects, such as the bid-ask bounce of Roll (1984) or informed trading driving up the bid-ask spread or the price impact (Kyle, 1985; Glosten and Milgrom, 1985).

Column (2) displays the results for fundamental volatility, the variability of the mid price, which by construction is less influenced by microstructural effects than the transitory volatility is. The effect on that measure of volatility by individual trading remains positive and statistically significant, as in column (1) and Tables 3 to 5. Interestingly, the effect of foreigners is no longer statistically significant, and that of local institutions is significant at only the $10 \%$ level. This is consistent with retail trading creating noise to a larger extent than the two groups of institutions, along the lines of the findings by Kaniel et al (2008) and De Long et al (1989).

Next, we explore the effects on the intraday liquidity measures. Columns (3) and (4) of Table 6 present the results of equations [6] and [7] using the effective bid-ask spread and depth, respectively. As described in section 4.2, we control for intraday volatility with an instrumental variable since we want to isolate any indirect effects on liquidity from volatility. The effect of each group in both dimensions of liquidity is positive: the coefficients in the spread model are negative for the trading of the three groups and statistically significant for the two local groups. The coefficients in the depth model are positive and statistically significant for each type of investor ${ }^{28}$.

\footnotetext{
${ }^{28}$ The results of trading activity and of the three control variables volatility, log of price and return agrees with previous panel data results for liquidity (Grullon, Kanatas, \& Weston, 2004; De Cesari, Espenlaub, \& Khurshed, 2011; Hendershott \& Moulton, 2011).
} 
Interestingly, as in volatility, the effect of individuals on liquidity is positive and significantly larger than that of local institutions, which is higher than that of foreigners, as indicated by the results of the Wald tests. The effect of individuals on liquidity is several times larger than the effect of institutions, both in the bid-ask spread and in the depth. This increased liquidity associated with retail trading can be explained by retail traders acting as the main liquidity providers, as reported by Agudelo et al (2019) in Colombia, by Lee et al. (1999) in Taiwan and by Barber and Odean (2001) in the US. Chordia, Roll, \& Subrahmanyam (2001) also report that depth rises when trading activity comes from uninformed investors. Overall, the evidence of Table 6 is consistent in presenting individuals as the main drivers of volatility, while at the same time, they are the most responsible for liquidity $(\mathrm{H} 1)$.

To further explore these relations, we again decompose the trading activity into two components, average trade value and number of trades for each type of investor, in the regressions of the intraday measures of volatility and liquidity, as presented in Table 7. Columns (1) and (2) reaffirm two findings of Table 4. First, the volatility-volume relation is driven more by the number of trades than by the average trade value. The Wald tests confirm that this differential effect is statistically significant at the $1 \%$ level. Second, while the effect of the average trade value by individuals is positive, that is not the case for the two groups of institutions. Again, this suggests a more careful execution of larger orders by both foreigners and local institutions, while large trades by retail traders appear to induce more noise.

In turn, columns (3) and (4) of Table 7 show that the positive effect of trading activity on liquidity, reported in Table 6, appears to come from both the number of trades of the three groups and the average retailer trade value, in terms of reduced spreads and larger depths. Since our trade and quote data cannot distinguish between active and passive trades by type of investor, we cannot 
be sure whose trading is providing liquidity. However, the results are consistent with the finding that the three groups contributing to liquidity, but retail traders contribute even more, especially with large passive orders.

In the absence of more detailed data, the results in Tables 6 and 7 are consistent with two nonmutually exclusive explanations of individual trading. First, individuals appear to be less informed, as their trading induce more volatility, both transitory and fundamental, and presumably lowers the adverse selection component of the spread. That intraday retail trading spurs volatility has also been reported in the US (Campbett et al, 2001) and Finland (Kyröläinen, 2008). Second, at least an important group of individual traders has a passive trading style and is important for liquidity provision. For example, such traders might be using more nonmarketable limit orders and/or behave as reversal traders. This behavior has been reported with transaction data in the US (Kaniek et al, 2008) and Taiwan (Lee et al, 2004). Both explanations render further support to H1. We offer some confirmatory evidence of the differences in trading style below in section 5.4.

With respect to the two institutional groups, local and foreigners, the results in Table 6 and 7 reflect a less intrusive effect on volatility, particularly on fundamental volatility, which is consistent with the hypothesis that institutions have superior information (H2). They also contribute to liquidity but to a lesser extent than individuals do. Moreover, in those intraday models, we fail to find that foreign trading has any large volatility effect, unlike some previous literature. To confirm this result, in the robustness test, we study whether foreign sells, particularly in times of financial stress, have an important impact on the volatility of the Colombian stock market in section 5.5. 
As a robustness test of the effects of trading on volatility, in Table 8, we report the results of the panel data model [3], using the alternative intraday measures of volatility introduced in section 4.3, while controlling for liquidity effects. Column (1) repeats the results of the mid-price (fundamental) volatility of Table 6 (column 2). Columns (2), (3) and (4) show the results with the bipower variation estimator [8], two-scale realized volatility measure [9] and median realized volatility [12], respectively. These four measures have been proposed as a way to mitigate the trading noise in the estimation of volatility based on transactional data.

We observe qualitatively the same results as those in the previous tables. Individual trading is clearly and by far the most directly associated with volatility for each of the four intraday measures. The coefficients of individual trading are between 5 and 15 times higher than those of the follower, the local institution trading. The difference is statistically significant, as shown by the Wald test. This effect is statistically significant even for the median realized volatility [12] by Andersen et al (2012) in column (4), arguably the measure that better controls for microstructural effects. Interestingly, the coefficients of the three types of traders are statistically significant, explaining this volatility measure, even though the effect of the market volatility is not significant, and the $\mathrm{R}^{2}$ of the regression is just 0,059 .

\section{$\underline{5.4 \text { Trading execution by type of trader. }}$}

Since we have interpreted the results of Tables 6-8 in terms of possible differences in trading style and degree of information among the three groups, here we explore some corroborating evidence. Specifically, the BVC database allows us to measure the average trading cost for each group and for buys and sells separately at the stock-day level. In addition, we measure the daily performance of each group as a proxy of information differences. 
We use a very simple measure of average buying (selling) cost, defined as the difference between the volume-weighted average daily buy (sell) price by investor " $j$ " in stock " $i$ ", relative to the volume-weighted average price for the stock-day, as follows:

$$
\begin{aligned}
& \text { Average_buy_cost } t_{i, j, t}=\left(V W A_{-} b u y_{\_} \text {price }_{i, j, t}-V W A_{-} \text {price }_{i t}\right) / V W A_{\_}{ }_{\text {price }}, t \\
& \text { Average_sell_cost }_{i j t}=\left(V W A \_p r i c e_{i t}-V W A \_s e l l \_p r i c e_{i j t}\right) / V W A \_p r i c e_{i, t}
\end{aligned}
$$

A positive (negative) value of Average_buy_cost (Average_sell_cost) implies as a more aggressive style of trading by a group of investors, with more frequent use of liquidity-demanding orders and less liquidity provision, or an intraday momentum style, with buying (selling) more at prices above (below) the average price of the trading session.

The results of trading cost measures [13] and [14] are presented in Table 9 for all three groups and for the total sample and the four size quartiles. To maintain comparability with the results of Tables 6-8, we restrict this estimation to the same period from August 23, 2010 to August 31, 2012. We observe that overall, both local groups, individuals and institutions, have negative buying and selling average costs. This negative cost is statistically significant in the whole sample and in most size quartiles. When comparing trading costs between them, t-test reveals that there is no statistically significant difference for sales (except a minor one in quartile 2 ). In contrast, the ttests show that individuals buy at lower average prices than institutions, a difference significant at the $1 \%$ level in the overall sample and size quartiles. As expected, the remaining investor group, foreigners, has a positive cost for both buys and sells that is statistically significant at the $1 \%$ level in the whole sample and in each of the four size quartiles. These results render support to the argument presented in section 5.2: Individuals are the main liquidity providers in the Colombian 
stock market, especially for incoming selling orders from other groups. Institutions are in second place in liquidity provision, while foreigners are clearly liquidity demanding traders.

Next, we measure the short-term performance by group, particularly timing, as a proxy for informed trading. Adapting a measure first proposed by Dvořák (2005), we estimate the daily performance as a function of the net buy of a type of investor " $j$ " in a stock " $i$ " multiplied by the next-day return of this stock, measured by the volume-weighted average prices, as follows:

$$
\text { Daily_Performance }_{i j t}=\operatorname{sign}\left(\text { Net_buy }_{i j t}\right) \times\left(\frac{V W A \_ \text {price }}{\text { it }+1}-1\right)
$$

A positive performance of a group of investors corresponds to an average good timing; i.e., the investors mostly buy on days before the price rises, and they mostly sell on days before the prices drop. Note that this measure is unaffected by the average buying or selling cost, [11] and [12], so it depends on only timing, the correct anticipation of the return the next day.

The results of this measure, summarized in Table 10, present contradictory results for the two local groups. On the one hand, local institutions have the best performance, with a positive average performance for the whole sample and the four size quartiles that is statistically significant in all cases but that of the largest stocks. This evidence is consistent with local institutions possessing an edge in terms of short-lived information. In contrast, local individuals present a consistent negative performance, which in all five cases is statistically significant at the $1 \%$ or $5 \%$ levels. This poor timing can be explained by individuals' less informed trading or alternatively by their passively providing liquidity to informed traders of the two other groups, i.e., selling (buying) with standing limit orders to investors that correctly anticipate prices going up (down). Finally, the performance of foreigners is not much different from zero. Their average performance, while positive, is three times lower than the performance of local institutions and only marginally 
significant in two out of five cases. This result is consistent with the idea that foreigners do not have much of an information edge in the Colombian market but neither do they have a disadvantage.

Taking together, the results in Tables 9 and 10 lend credit to the explanation provided in section 5.3: Local individuals are the main liquidity providers of the Colombian Stock Market and represent most of the noise traders, with an inferior performance evident in poor timing. This is consistent with the evidence of individual trading as the main driver of both daily and intraday volatility and liquidity, discussed in H1 (Section 2). In the same line, Lee et al (2004) and Barber et al. (2009) report that individuals are the main liquidity providers and noise traders in Taiwan, and Choi and Choi (2018) report that individual trading generates systematic noise trading in Korea.

Institutions, in turn, are good at executing trades and appear to have an information advantage, at least at a daily frequency. Validating evidence of this is provided by Agudelo et al (2019) for BVC, who use performance measures in monthly and yearly periods and find a positive relation between institutional trading and the adverse selection component of the bid-ask spread. Barber et al. (2008) also present evidence of superior performance and trading execution by local institutions in Taiwan, which they attribute to superior information. Using quarterly institutional holdings in 32 countries, Ferreira, Matos, Pereira, and Pires (2017) report that local institutions have superior performance than foreigners, and their behavior is consistent with superior information, especially in countries with higher information asymmetry and lower investor protection. Consistent with $\mathrm{H} 2$, informed trading by local institutions can explain why their trading creates less volatility than that of individuals, in spite of their greater share of trading and larger average trading value. 
Finally, foreigners are aggressive traders, paying larger average transaction costs for both buys and sells. In terms of performance, they appear in the middle, as we may expect if they have no information edge, unlike local institutions, and if they are not noise traders providing liquidity for informed investors, unlike local individuals. The more aggressive trading style of foreigners has also been documented in intraday data in Korea by Choe et al., (2005), with daily stock-data in Colombia by Agudelo et al (2019), and indirectly, as price pressure at market-day level, by Griffin et al (2004) for a group of six Asian emerging markets. Finally, the trading executing evidence on the two institutional groups, foreigners and locals, is also consistent with the hypothesis that their trading does not create as much volatility as that of individuals because their trading is relatively more informed and does not provide much liquidity due to their more aggressive trading style, consistent with $\mathrm{H} 2$ and $\mathrm{H} 3$.

\subsection{The effect of foreigners during times of financial stress.}

As discussed in $\mathrm{H} 3$, the previous literature does not suggest a clear expected effect of foreigners on stock volatility in an emerging market. On the one hand, some early studies indicate that large foreign flows, especially net selling, create excess volatility (Bae et al, 2004; Wang, 2007). On the other hand, foreigners are almost exclusively institutional investors, so we should expect that, as with local institutions, their trading has a lower effect on volatility than trading by individuals. Moreover, the results presented so far indicate that foreigners are the group of investors that is least responsible for volatility in the Colombian Stock Market.

As a robustness test, we investigate the effect of foreign trading in volatility during times of financial stress. This can be motivated in two ways. The literature on foreign flows has documented 
that international factors ("push factors") drive foreign flows in and out of emerging markets (Griffin et al, 2004; Richards, 2005). In addition, there is evidence of volatility transmission from US markets to emerging ones, especially during financial crises (e.g., Weber, 2013; Rejeb and Arfaoui, 2016). Bringing these two ideas together, it is natural to assume that foreign flows might be responsible of volatility peaks in emerging markets, if only (or especially) during times of stress, when they might be transmitting volatility from developed markets through aggressive sells.

We use the CBOE Market Volatility Index (VIX) as an indicator of worldwide financial stress. The VIX is a commonly used measure of market risk sentiment (Gromb and Vayanos, 2002). We use two alternative definitions for days of worldwide financial stress. First, we use days of high VIX, i.e., when this index is above the $90^{\text {th }}$ percentile of its distribution in the sampled period. Second, we consider days with large VIX increases, i.e., when the daily change of VIX is above its corresponding $90^{\text {th }}$ percentile. Note that the sample includes the subprime crisis from 20072008 and the sovereign debt crisis of the Euro zone from 2009-2011, which both originated in developed markets and were periods where presumably, foreign flows could have transmitted volatility to emerging markets. Both crises involved many days of financial stress according to either definition.

Table 11 presents the results of the panel data model [2] that focuses on times of financial stress. Column (1) reproduces the base result in the total sample for comparison purposes (column 1, Table 3). columns (2) and (3) present the results of the model restricted to high VIX days. columns (4) and (5), in turn, display the results for days with large VIX increases. In columns (3) and (5), we remove the volatilities of the stock market index and the foreign exchange rate as explanatory variables to check the results when not controlling for market-wide volatility effects. Finally, columns (6) and (7) correspond to the model run on the whole sample but including a dummy 
variable for days of large VIX, d_high_vix, as well as the interactions of the three trading variables with the dummy variable.

The results in columns (2) to (5) show no qualitative difference from those presented so far. Trading by foreigners still has the lowest effect of the three types on stock volatility, even though the model focuses on a subsample of days of particular financial stress. This is true for both definitions of times of stress, and the differences between the groups of investors are highly significant in all cases (in omitted Wald tests). In columns (3) and (5), we examine the possibility that a higher effect of foreigners in times of stress might be subsumed by the market index or exchange rate volatilities by removing those two variables. However, this is not the case. The coefficient of foreign trading remains approximately the same in column (3) and increases in column (5), but in both cases, it is still well below the coefficients for the trading of both local groups. In turn, the results of the model with interacting variables, in columns (6) and (7), show that, as expected, times of stress are more volatile, as indicated by the highly significant and positive effect of the dummy variable. However, the interaction effect of the high VIX dummy with foreign trading, negative and highly significant, indicates again that foreign trading does not explain more volatility in those days, but rather the opposite. This is also true for local institutions, but not for local individuals. In unreported results, we also separate the trading variables by buys and sells and include interactions with the dummies of times of stress, but the results remain qualitatively the same: times of stress are intrinsically more volatile, independent of the trading patterns of the three groups of investors. Thus, we conclude that foreign trading is less related to increasing volatility than local trading in an emerging stock market such as BVC, even in times of financial stress. Although we find evidence that stocks are more volatile on those days, the relation 
of the trading of the three groups of investors to volatility is qualitatively similar to that of normal days.

\section{$\underline{5.6 \text { Effects of Short-Term vs Long-Term local institutions }}$}

The BVC database allows us to decompose the institutional investor group into short-term and long-term firms. We group together brokerage firms and family offices as short-term institutional investors who actively trade in the Colombian stock market. Agudelo et al (2019) indicate that these two types of firms are responsible for approximately $69 \%$ the number of trades by Colombian institutions in the stock market. In the long-term category, we classify pension funds, insurance companies, mutual funds, investment trusts and investment companies. Given their ambiguous role in investment in a stock market, we exclude other financial intermediaries such as banks, which only removes $0,4 \%$ of the total trading value. As discussed in $\mathrm{H} 2$, we expect a lower effect on volatility by the trading activity of the long-term institutions. We hypothesize that their focus on the long term makes them more patient investors who are not so driven by the search for shortterm gains and who have a less aggressive style of trading than short-term firms.

We estimate the differential effects among the two groups of local institutions on intraday volatility and liquidity measures. For this, we run panel data models [2], [3], [6] and [7], replacing the institutions' trading by the value traded by short-term and long-term investors. The results are presented in Table 12.

We find that the short-term group has a larger effect on total volatility that is approximately two times greater than the effect of the long-term institutions, a highly statistically significant difference (column 1). As given by the Wald test, the effects of both groups of local institutions on volatility are significantly higher than the effects of foreigners but significantly lower than the 
effects of individuals. The effects are similar concerning fundamental volatility (column 2), with two exceptions: the effects of short-term institutions are no longer significantly higher than the effects of long-term institutions, which are in turn are no longer significantly higher than the effects of foreigners.

Columns (3) and (4) report the coefficients of trading of the four groups in the panel data regressions of liquidity measures. The trading of the two types of local institutions contributes to smaller bid-ask spreads, with no great difference between them. Nevertheless, their effect is statistically higher than that of foreigners and lower than that of retail traders. The contribution to the depth from both local institutions is still positive but significantly larger for short-term firms than for long-term firms.

In summary, the prior results show that the short-term institutional group has effects on volatility and liquidity that lie between those of long-term institutions and local individuals, preserving the relative order reported in sections 5.2 and 5.3. Compared with the trading by longterm institutions, the trading by short-term institutions induces more volatility, both total and fundamental, but at the same time creates more liquidity, especially larger depths. Conversely, long-term firms exert more of a stabilizing effect on volatility. This is consistent with long-term institutions having a relative informational edge and a less disruptive trading style. Both findings are coherent with the average transaction costs and performance measures for both types of local institutions reported in BVC by Agudelo et al (2019).

\section{Conclusions}


This paper investigates the differential effects of three types of investors, local institutions, foreigners, and local individuals, on the trading activity in an emerging market. The results show that local individual trading has the largest effect on stock volatility, followed by trading by local institutions and finally trading by foreigners. This relative order is robust to testing selling and buying activities separately, examining the effect of average trade value and number of trades, splitting the sample period in two, testing it in four size quartiles, and using intraday measures of volatility. This is consistent with a characterization of individuals as "noise traders" and uninformed liquidity providers, as confirmed by their relative inferior daily performance and larger positive effect on two intraday measures of liquidity. The results are consistent with individuals, as a group, acting as boundedly rational agents, either trading for pure liquidity needs or wishfully thinking that they are acting on information. Of course, this does not rule out that there might be an important number of informed and successful retail traders, for example, acting on insider tips or using superior expertise on the market, as anecdotal evidence suggests.

Focusing on the local institutional group, we find that short-term institutional investors tend to have an intermediate effect between the effect of long-term institutional investors and individuals. The long-term group and foreigners appear to be more sophisticated investors and more likely to be informed traders than individuals and short-term institutions and have a relative stabilizing role in the market. Foreigners appear to induce the least volatility, contrary to what is assumed by some of the previous literature. We find that this result is robust not only to the different samples and measures indicated above but also when the models focus on times of worldwide financial stress, as proxied by the VIX.

In terms of regulatory prospects, since liquidity is a major concern in emerging markets, the results of this study suggest that exchanges should promote trading by retail investors, for the gains 
in liquidity, in spite of the loss in efficiency and the larger volatility. This is, of course, just a second-best solution that is appropriate for financial markets in the early stages of development. Ideally, as in developed markets, individuals should invest through institutions, such as funds, institutions should do most of the trading, and some specialized firms should act as designated market makers.

\section{References}

Agudelo, D. A., Byder, J., \& Yepes-Henao, P. (2019). Performance and informed trading. comparing foreigners, institutions and individuals in an emerging stock market. Journal of International Money and Finance, 90, 187-203.

Agudelo, D. A., Gutiérrez Daza, Á., \& Múnera Montoya, N. J. (2014). Market quality and structural changes in the trading system: The case of X-Stream on the Colombian stock exchange. Academia, 27(3), 324-340.

Admati, A. R., and Pfleiderer, P. (1988). A theory of intraday patterns: Volume and price variability. The Review of Financial Studies, 1(1), 3-40.

Alizadeh, S., Brandt, M. W., \& Diebold, F. X. (2002). Range-based estimation of stochastic volatility models. Journal of Finance, 57(3), 1047-1091.

Andersen, T. G., and Bollerslev, T. (1998). Answering the Skeptics: Yes, Standard Volatility Models do Provide Accurate Forecasts. International Economic Review, 39(4), 885-905.

Andersen, T. G., Bollerslev, T., Diebold, F. X., and Labys, P. (2001). The distribution of realized exchange rate volatility. Journal of the American statistical association, 96(453), 42-55.

Andersen, T. G., Dobrev, D., and Schaumburg, E. (2012). Jump-robust volatility estimation using nearest neighbor truncation. Journal of Econometrics, 169(1), 75-93.

At-Sahalia, Y., Mykland, P. A., and Zhang, L. (2011). Ultra high frequency volatility estimation with dependent microstructure noise. Journal of Econometrics, 160(1), 160-175.

Bae, K.-H., Chan, K., and Ng, A. (2004). Investibility and Return Volatility. Journal of Financial Economics, 71, 239-263.

Bandi, F. M., and Russell, J. R. (2006). Separating microstructure noise from volatility. Journal of Financial Economics, 79(3), 655-692.

Barber, B. M., Lee, Y. T., Liu, Y. J., and Odean, T. (2008). Just how much do individual investors lose by trading. Review of Financial Studies, 22(2), 609-632.

Barber, B. M., and Odean, T. (2001). The internet and the investor. Journal of Economic Perspectives, 15(1), 41-54.

Barber, B. M., and Odean, T. (2004). Online investors: do the slow die first?. Review of Financial Studies, 15(2), 455-488. 
Barber, B. M., and Odean, T. (2007). All that glitters: The effect of attention and news on the buying behavior of individual and institutional investors. Review of Financial Studies, 21(2), 785-818.

Barclay, M. J., and Warner, J. B. (1993). Stealth trading and volatility: Which trades move prices?. Journal of Financial Economics, 34(3), 281-305.

Barndorff-Nielsen, O. E., and Shephard, N. (2004). Power and Bipower Variation with Stochastic Volatility and Jumps. Journal of Financial Econometrics, 2(1), 1-48.

Barrot, J. N., Kaniel, R., and Sraer, D. (2016). Are retail traders compensated for providing liquidity?. Journal of Financial Economics, 120(1), 146-168.

Bekaert, G., and Harvey, C. R. (1997). Emerging equity market volatility. Journal of Financial Economics, 43(1), 29-77.

Bekaert, G., and Harvey, C. R. (2003). Emerging markets finance. Journal of Empirical Finance, 10(1-2), $3-55$.

Black, F. (1986). Noise. Journal of Finance, 41(3), 529-543.

BVC (2012), Informe de gestión. https://www.bvc.com.co/pps/tibco/portalbvc/Home/Accionistas

Campbell, J. Y., Lettau, M., Malkiel, B. G., and Xu, Y. (2001). Have individual stocks become more volatile? An empirical exploration of idiosyncratic risk. Journal of Finance, 56(1), 1-43.

Chan, K., \& Fong, W. M. (2000). Trade size, order imbalance, and the volatility-volume relation. Journal of Financial Economics, 57(2), 247-273.

Chen, Z., Du, J., Li, D., \& Ouyang, R. (2013). Does foreign institutional ownership increase return volatility? Evidence from China. Journal of Banking \& Finance, 37(2), 660-669.

Chiang, M. H., and Wang, L. M. (2011). Volatility contagion: A range-based volatility approach. Journal of Econometrics, 165(2), 175-189.

Chinn, M. D., and Ito, H. (2006). What matters for financial development? Capital controls, institutions, and interactions. Journal of Development Economics, 81(1), 163-192.

Choe, H., Kho, B. C., and Stulz, R. M. (2005). Do domestic investors have an edge? The trading experience of foreign investors in Korea. Review of Financial Studies, 18(3), 795-829.

Choi, P. M. S., \& Choi, J. H. (2018). Is individual trading priced in stocks?. Journal of International Money and Finance, 85, 76-92.

Chordia, T., Roll, R., \& Subrahmanyam, A. (2001). Market liquidity and trading activity. Journal of Finance, 56(2), 501-530.

Coval, J. D., and Moskowitz, T. J. (1999). Home Bias at Home: Local Equity Preference in Domestic Portfolios. Journal of Finance, 54(6), 2045-2073.

David, A. (1997). Fluctuating Confidence in Stock Markets : Implications for Returns and Volatility. Journal of Financial and Quantitative Analysis, 32(4), 427-462.

De Long, J. B., Shleifer, A., Summers, L. H., and Waldmann, R. J. (1989). The size and incidence of the losses from noise trading. Journal of Finance, 44(3), 681-696.

De Long, B., Shleifer, A., Summers, L., and Waldmann, R. (1990). Noise Trader Risk in Financial Markets. Journal of Political Economy, 98(4), 703-738.

Driscoll, J. C., and Kraay, A. C. (1998). Consistent Covariance Matrix Estimation with Spatially Dependent Panel Data. Review of Economics and Statistics, 80(4), 549-560.

Dvořák, T. (2005). Do Domestic Investors Have an Information Advantage ? Evidence from Indonesia. Journal of Finance, 60(2), 817-839.

Easley, D., and O'Hara, M. (1987). Price, trade size, and information in securities markets. Journal of Financial Economics, 19(1), 69-90. 
Ferreira, M. A., Matos, P., Pereira, J. P., \& Pires, P. (2017). Do locals know better? A comparison of the performance of local and foreign institutional investors. Journal of Banking \& Finance, 82, 151-164.

Foucault, T., Sraer, D., and Thesmar, D. J. (2011). Individual investors and volatility. Journal of Finance, 66(4), 1369-1406.

French, K. R., and Roll, R. (1986). Stock return variances: The arrival of information and the reaction of traders. Journal of Financial Economics, 17(1), 5-26.

FTSE (2017). FTSE Annual Country Classification Review, September 2017. Retrieved from www.ftse.com/products/downloads/FTSE-Country-Classification-Update_latest.pdf, on Dec. 2017.

Gabaix, X., Gopikrishnan, P., Plerou, V., and Stanley, H. E. (2006). Institutional investors and stock market volatility. Quarterly Journal of Economics, 121(2), 461-504.

Galeotti, M., and Schiantarelli, F. (1994). Stock Market Volatility and Investment: Do Only Fundamentals Matter? Economica, 61(242), 147-165.

Glosten, L. R., and Milgrom, P. R. (1985). Bid, ask and transaction prices in a specialist market with heterogeneously informed traders. Journal of Financial Economics, 14(1), 71-100.

Goyenko, R. Y., Holden, C. W., and Trzcinka, C. A. (2009). Do liquidity measures measure liquidity? Journal of Financial Economics, 92(2), 153-181.

Griffin, J. M., Nardari, F., and Stulz, R. M. (2004). Are daily cross-border equity flows pushed or pulled?. Review of Economics and Statistics, 86(3), 641-657.

Griffin, J. M., Nardari, F., and Stulz, R. M. (2006). Do investors trade more when stocks have performed well? Evidence from 46 countries. Review of Financial Studies, 20(3), 905-951.

Grinblatt, M., and Keloharju, M. (2000). The investment behavior and performance of various investor types : a study of Finland's unique data set. Journal of Financial Economics, 55(1), $43-67$.

Grinblatt, M., Titman, S., and Wermers, R. (1995). Momentum Investment Strategies, Portfolio Performance, and Herding: A Study of Mutual Fund Behavior. American Economic Review, 85(5), $1088-1105$.

Gromb, D., and Vayanos, D. (2002). Equilibrium and welfare in markets with financially constrained arbitrageurs. Journal of Financial Economics, 66(2), 361-407.

Grullon, G., Kanatas, G., and Weston, J. P. (2004). Advertising , Breadth of Ownership , and Liquidity. Review of Financial Studies, 17(2), 439-461.

Hamao, Y., and Mei, J. (2001). Living with the "enemy": An analysis of foreign investment in the Japanese equity market. Journal of International Money and Finance, 20(5), 715-735.

Harris, L. (2003). Trading and exchanges: Market microstructure for practitioners. Oxford University Press.

Hendershott, T., and Moulton, P. C. (2011). Automation, speed, and stock market quality: The NYSE's hybrid. Journal of Financial Markets, 14(4), 568-604.

Hoechle, D. (2007). Robust standard errors for panel regressions with cross-sectional dependence. Stata Journal, 7(3), 281-312.

Holmes, P., and Wong, M. W. (2001). Foreign investment, regulation and price volatility in South-east Asian stock markets. Emerging Markets Review, 2(4), 371-386.

Huang, R. D., and Shiu, C.-Y. (2009). Local Effects of Foreign Ownership in an Emerging Financial Market: Evidence from Qualified Foreign Institutional Investors in Taiwan. Financial Management, 38(3), 567-602.

Huang, R. D., and Stoll, H. R. (1996). Dealer versus auction markets : A paired comparison of execution costs on NASDAQ and the NYSE. Journal of Financial Economics, 41, 313-357 
Jones, C. M., Kaul, G., and Lipson, M. L. (1994). Transactions, volume, and volatility. Review of Financial Studies, 7(4), 631-651.

Kaniel, R., Saar, G., and Titman, S. (2008). Individual Investor Trading and Stock Returns Investor Trading and Returns. Journal of Finance, 63(1), 273-310.

Kaniel, R., Liu, S., Saar, G., and Titman, S. (2012). Individual investor trading and return patterns around earnings announcements. Journal of Finance, 67(2), 639-680.

Karpoff, J. M. (1987). The relation between price changes and trading volume: A survey. Journal of Financial and Quantitative Analysis, 22(1), 109-126.

Kavajecz, K. A, and Odders-White, E. R. (2001). Volatility and market structure. Journal of Financial Markets, 4(4), 359-384.

Kupiec, P. (1991). Stock Market Volatility in OECD Countries: Recent Trends, Consequences for the real economy and proposals for reform. OECD Economic Studies, 17, 31-62.

Kyle, A. S. (1985). Continuous Auctions and Insider Trading. Econometrica, 53(6), 1315-1335.

Kyröläinen, P. (2008). Day trading and stock price volatility. Journal of Economics and Finance, 32(1), 75-89.

Lakonishok, J., Shleifer, A., and Vishny, R. W. (1992). The impact of institutional trading on stock prices. Journal of Financial Economics, 32(1), 23-43.

Lee, Y.-T., Lin, J.-C., and Liu, Y.-J. (1999). Trading patterns of big versus small players in an emerging market: An empirical analysis. Journal of Banking and Finance, 23(5), 701-725.

Lee, Y. T., Liu, Y. J., Roll, R., and Subrahmanyam, A. (2004). Order imbalances and market efficiency: Evidence from the Taiwan Stock Exchange. Journal of Financial and Quantitative Analysis, 39(2), 327-341.

Lin, C., Lee, Y., and Chiu, C. (2009). Structural changes in foreign investors' trading behavior and the corresponding impact on Taiwan's stock market. Research in International Business and Finance, 23, 78-89.

Malmendier, U., and Shanthikumar, D. (2007). Are small investors naive about incentives? Journal of Financial Economics, 85(2), 457-489.

Montiel, P., and Reinhart, C. M. (1999). Do capital controls and macroeconomic policies influence the volume and composition of capital flows? Evidence from the 1990s. Journal of International Money and Finance, 18(4), 619-635.

$\mathrm{Ng}$, L., and Wu, F. (2007). The trading behavior of institutions and individuals in Chinese equity markets. Journal of Banking and Finance, 31(9), 2695-2710.

Ozenbas, D., Schwartz, R. A., and Wood, R. A. (2002). Volatility in US and European equity markets: An assessment of market quality. International Finance, 5(3), 437-461.

Pagano, M. S., and Schwartz, R. A. (2003). A closing call's impact on market quality at Euronext Paris. Journal of Financial Economics, 68(3), 439-484.

Poon, S.-H., and Granger, C. W. J. (2003). Poo Granger JEL 2003 Forecasting volatility in financial markets. A review. Journal of Economic Literature, 41, 478-539.

Rejeb, A. B., \& Arfaoui, M. (2016). Financial market interdependencies: A quantile regression analysis of volatility spillover. Research in International Business and Finance, 36, 140-157.

Richards, A. (2005). Big Fish in Small Ponds: The Trading Behavior and Price Impact of Foreign Investors in Asian Emerging Equity Markets. Journal of Financial and Quantitative Analysis, 40(1), 1.

Roll, R. (1984). A simple measure of the implicit bid-ask spread in an efficient market. Journal of Finance., 39(4), 1127. 
Schwert, G. W. (1989). Why Does Stock Market Volatility Change Over Time? Journal of Finance, 45(5), 1115-1151.

Shiller, R. J. (2003). From Efficient Markets Theory to Behavioral Finance. Journal of Economic Perspectives, 17(1), 83-104.

Tian, X., Do, B., Duong, H. N., and Kalev, P. S. (2015). Liquidity provision and informed trading by individual investors. Pacific-Basin Finance Journal, 35, 143-162.

Tsai, S.-C. (2014). Individuals' trading prior to earnings announcements. Journal of Business Finance and Accounting, 41(9-10), 1124-1156.

Venezia, I., Nashikkar, A., \& Shapira, Z. (2011). Firm specific and macro herding by professional and amateur investors and their effects on market volatility. Journal of Banking \& Finance, 35(7), 15991609.

Wang, J. (2007). Foreign equity trading and emerging market volatility: Evidence from Indonesia and Thailand. Journal of Development Economics, 84(2), 798-811.

Weber, E. (2013). Simultaneous stochastic volatility transmission across American equity markets. Quarterly Review of Economics and Finance, 53(1), 53-60.

WFE: World Federation of Exchanges (2016). Database of Market Capitalization by Exchanges at the end of 2015. Retrieved from www.world-exchanges.org, on June, 2016.

Yang, D., and Zhang, Q. (2000). Drift Independent Volatility Estimation Based on High, Low, Open, and Close Prices. Journal of Business, 73(3), 477-492. 


\section{Figure 1}

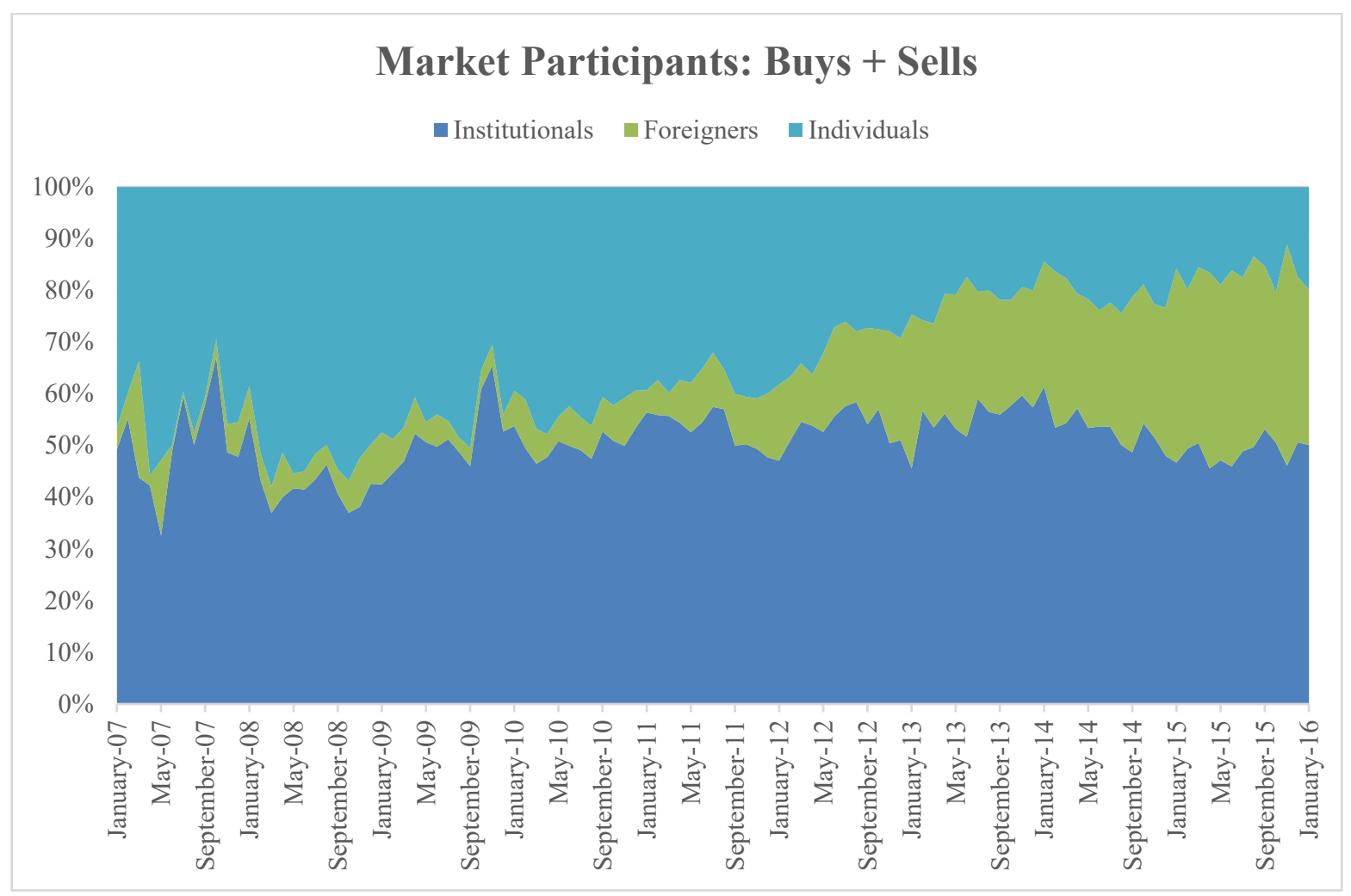

Figure 1 shows the market share of trading activity by each type of investor: local institutions, local individuals and foreigners; for the sample period from January 1, 2007 to January 29, 2016. Data are provided by the Colombia Stock Exchange (BVC). 


\section{Table 1. Summary statistics for type of investor}

\begin{tabular}{|c|c|c|c|c|c|c|c|c|c|c|c|c|}
\hline \multirow[b]{4}{*}{ Quartile: } & \multicolumn{12}{|c|}{ Panel A: Daily average traded value (US Dollars) } \\
\hline & \multirow[b]{3}{*}{$\mathrm{N}$} & \multicolumn{5}{|c|}{ Foreigners } & \multicolumn{4}{|c|}{ Local Institutions } & \multicolumn{2}{|c|}{ Local Individuals } \\
\hline & & \multirow{2}{*}{\multicolumn{2}{|c|}{$\begin{array}{c}\text { Mean Median } \\
\text { (thousands) }\end{array}$}} & \multicolumn{2}{|c|}{$\mathrm{t}$-test } & & Mean & Median & \multirow{2}{*}{\multicolumn{2}{|c|}{$\begin{array}{c}\text { t-test } \\
> \\
\text { Individuals } \\
\end{array}$}} & \multirow{2}{*}{\multicolumn{2}{|c|}{$\begin{array}{c}\text { Mean Median } \\
\text { (thousands) }\end{array}$}} \\
\hline & & & & $\begin{array}{c}> \\
\text { Institution }\end{array}$ & $\begin{array}{c}> \\
\text { Individuals }\end{array}$ & & (thous & & & & & \\
\hline Total & 43.479 & 855,5 & 122,6 & $-55,3 * * *$ & $-40,3$ & *** & $2.961,1$ & 844,8 & 34,4 & *** & $1.923,4$ & 567,3 \\
\hline Q4 & 10.451 & $1.517,6$ & 420,1 & $-40,7 * * *$ & $-28,7$ & $* * *$ & $5.370,6$ & $2.173,4$ & 24,7 & *** & $3.465,4$ & $1.209,0$ \\
\hline Q3 & 14.819 & $1.023,5$ & 269,4 & $-28,0 * * *$ & $-13,3$ & $* * *$ & $3.480,8$ & $1.187,4$ & 26,8 & $* * *$ & $1.768,9$ & 556,4 \\
\hline Q2 & 8.404 & 489,6 & 93,8 & $-29,9 * * *$ & $-24,1$ & $* * *$ & $1.551,2$ & 669,4 & 10,1 & $* * *$ & $1.271,1$ & 523,9 \\
\hline Q1 & 9.805 & 209,6 & 0,1 & $-17,8 * * *$ & $-19,4$ & $* * *$ & 815,8 & 231,5 & $-5,7$ & $* * *$ & $1.072,3$ & 283,2 \\
\hline
\end{tabular}

Panel B: Daily number of trades

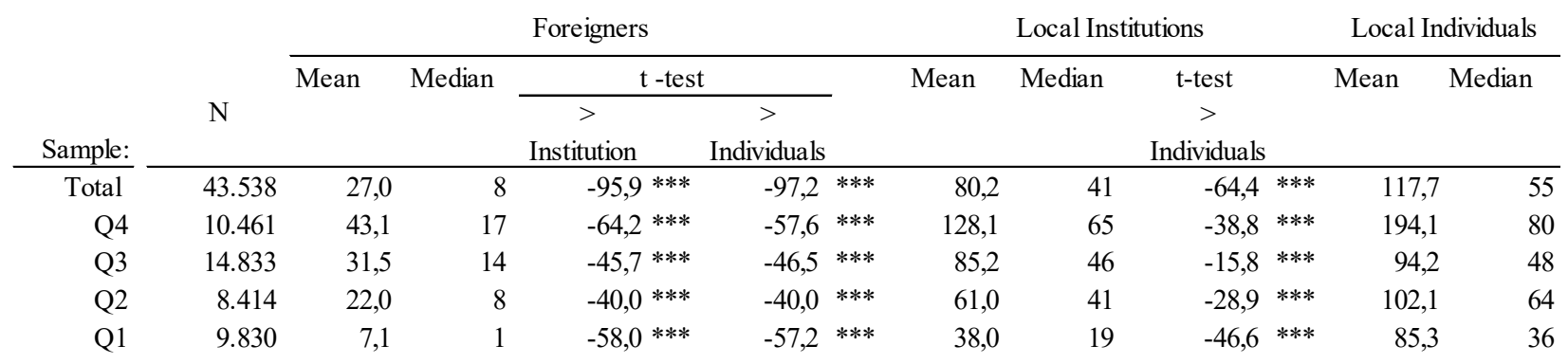

Panel C: Value by trade (US Dollars)

\begin{tabular}{|c|c|c|c|c|c|c|c|c|c|c|}
\hline \multirow[b]{3}{*}{ Sample: } & & \multicolumn{4}{|c|}{ Foreigners } & \multicolumn{3}{|c|}{ Local Institutions } & \multicolumn{2}{|c|}{ Local Individuals } \\
\hline & \multirow[b]{2}{*}{$\mathrm{N}$} & Mean & & \multicolumn{2}{|c|}{$\mathrm{t}$-test } & \multirow{2}{*}{\multicolumn{2}{|c|}{$\begin{array}{c}\text { Mean Median } \\
\text { (thousands) }\end{array}$}} & \multirow{2}{*}{$\begin{array}{c}\text { t-test } \\
\quad> \\
\text { Individuals } \\
\end{array}$} & \multirow{2}{*}{\multicolumn{2}{|c|}{$\begin{array}{c}\text { Mean Median } \\
\text { (thousands) }\end{array}$}} \\
\hline & & (thous & & $\begin{array}{c}> \\
\text { Institution }\end{array}$ & $\begin{array}{c}> \\
\text { Individuals }\end{array}$ & & & & & \\
\hline Total & 43.479 & 26,2 & 12,0 & $-3,4 * *$ & $3,5 * *$ & 30,2 & 20,2 & $57,9 * * *$ & 13, & 10,5 \\
\hline Q4 & 10.451 & 30,3 & 20,6 & $-16,8 * * *$ & $18,0 * * *$ & 38,2 & 29,5 & $40,6 * * *$ & 17 , & 14,4 \\
\hline Q3 & 14.819 & 39,4 & 16,3 & 0,1 & $2,5 * *$ & 36,8 & 25,3 & $42,4 * * *$ & 14 , & 11,8 \\
\hline Q2 & 8.404 & 15,4 & 9,6 & $-15,6 * * *$ & $-0,7$ & 22,5 & 16,0 & $18,4 * * *$ & 11, & 8,4 \\
\hline Q1 & 9.805 & 10,9 & 0,1 & $-15,2 * * *$ & 0,2 & 18,2 & 10,8 & $20,1 * * *$ & 9 , & 7,5 \\
\hline
\end{tabular}

This table reports the summary statistics of trading by the three types of investors, for the overall market and for the four size quartiles, from January 1, 2007 to January 29, 2016, based on data provided by Colombia Stock Exchange (BVC). Two-tailed t-statistics for the mean differences between groups are provided. N: Number of stock-days. ${ }^{*}, * *, * * *$ : Statistical significance at the $10 \%, 5 \%$ and $1 \%$ levels, respectively. 
Table 2. Summary statistics of stock volatility

\begin{tabular}{rrrrrr}
\multirow{2}{*}{$\begin{array}{c}\text { Number of } \\
\text { stocks }\end{array}$} & & Mean & $\begin{array}{c}\text { Standard } \\
\text { Deviation }\end{array}$ & Median & $\begin{array}{c}\text { Average } \\
\text { Autocorrelation }\end{array}$ \\
\cline { 2 - 5 } & & & & & \\
44 & 42.928 & $1,95 \%$ & $1,84 \%$ & $1,50 \%$ & $39,6 \%$ \\
9 & 10.404 & $1,72 \%$ & $1,32 \%$ & $1,40 \%$ & $37,1 \%$ \\
10 & 14.778 & $1,97 \%$ & $1,90 \%$ & $1,54 \%$ & $35,4 \%$ \\
12 & 8.319 & $1,78 \%$ & $1,57 \%$ & $1,38 \%$ & $39,9 \%$ \\
13 & 9.427 & $2,32 \%$ & $2,32 \%$ & $1,79 \%$ & $43,8 \%$
\end{tabular}

This table presents the summary statistics of daily volatility for Colombian stocks from January 1 , 2007 to January 29, 2016, for the whole sample and the four size quartiles. Volatility is measured as $\quad \sigma_{i, t}=\ln \left(\right.$ High_price $\left._{i, t}\right)-\ln \left(\right.$ Low_price $\left._{i, t}\right)$ where High_price $e_{i, t}$ and Low_price L $_{i, t}$ correspond to the maximum and minimum trading price of stock $i$ in day $t$, respectively. The results are based on data provided by Colombia Stock Exchange (BVC). N: Number of stock-days. 
Table 3. Regressing stock volatility against traded value by type of investor

Dependent variable: $\ln \left(\sigma_{i t}\right)$

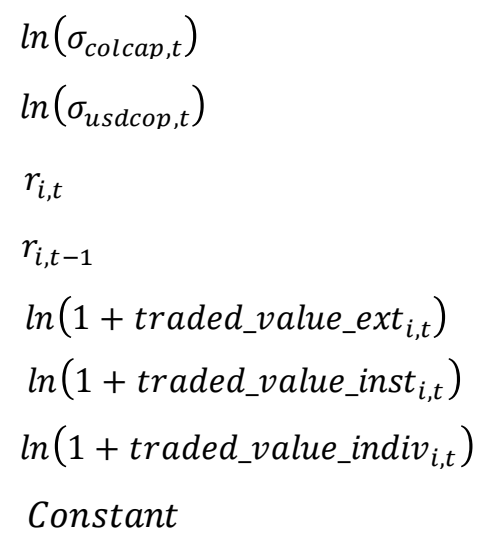

\section{Wald Test}

traded_value_ext $_{i, t}=$ traded_value_inst $_{i, t} \quad 43,04 * * *$

traded_value_inst $t_{i, t}=$ traded_value_indiv $_{i, t} 139,9 * * *$

traded_value_ext $t_{i, t}=$ traded_value_indiv $_{i, t}$ 357,3***
(1)

(2)

Total Sample

$0,4148^{* * *}$
$0,1053^{* * *}$

$0,1894^{* * *}$

$-0,4122$

$0,0082 * * *$

$0,0276^{* * *}$

$0,1097 * * *$

$-4,7739^{* * *}$

36.820

0,205

37

\begin{tabular}{l}
$2007-2011$ \\
\hline $0,4487^{* * *}$ \\
$0,0377^{* * *}$ \\
$1,4193^{* * *}$ \\
0,5052 \\
$0,0022^{* * *}$ \\
$0,0189^{* * *}$ \\
$0,1486^{* * *}$ \\
$-5,5185^{* * *}$ \\
17.401 \\
0,240 \\
29
\end{tabular}

29

$25,99 * * *$
$134,9 * * *$
$223 * * *$

(3)

2012-2016

$0,3868^{* * *}$
$0,1742^{* * *}$
0,1018
$-1,2419^{* * *}$
$0,0109^{* * *}$
$0,0471^{* * *}$
$0,1041^{* * *}$
$-4,9034^{* * *}$
19.419
0,210
30

30

$29,90 * * *$
$19,78 * * *$
$129,7 * * *$

(4)

Quartile 1

$0,2936^{* * *}$

$0,1680^{* * *}$

$0,1868^{* * *}$

0,1516

$0,0054 * * *$

$0,0202 * * *$

$0,1665^{* * *}$

$-5,6871^{* * * *}$

6.858

0,224

11

$13,12^{* * *}$
$66,98^{* * *}$
$107,1 * * *$

(5)

(6)

(7)

Quartile 2

Quartile 3

Quartile 4

$0,4924 * * *$

$0,1071^{* * *}$

$0,0754 * * *$

$0,0910^{* * *}$

0,4601

$-0,0345$

0,0321

$-0,4032$

$-1,0625^{* *}$

$-0,4835$

$0,0051^{* * *}$

$0,0129 * * *$

$0,0070^{* * *}$

$0,0190 * * *$

$0,0431 * * *$

$0,0276^{* * *}$

$0,1649 * * *$

$0,0690 * * *$

$0,0695 * * *$

$-5,9404 * * * \quad-4,2799 * * *$

$-3,7761 * * *$

7.540

0,205

13.084

9.338

0,229

9

10

$\begin{array}{lll}4,167 * * & 20,22 * * * & 8,370 * * * \\ 110,3 * * * & 4,737 * * & 9,755 * * * \\ 293,1 * * * & 59,53 * * * & 46,81 * * *\end{array}$

This table reports the results of panel data models regressing the stock price volatility $\ln \left(\sigma_{i t}\right)$ against the traded value by type of investor, at daily frequency, as in [2]. Column (1) presents the results for the total sample from January 1, 2007 to January 29, 2016. Columns (2) and (3) present the corresponding results for the two half-periods. Columns (4) to (7) show the estimations for the four size quartiles. Wald tests that compare the three trading activity coefficients are reported. The panel data models are estimated with fixed effects and the Driscoll \& Kraay (1998) covariance matrix estimator. The data come from the Colombia Stock Exchange (BVC) and Bloomberg. $\mathrm{N}$ : Number of stock-days. *, **, ***: Statistical significance at the $10 \%, 5 \%$ and $1 \%$ levels, respectively. 
Table 4. Regressing stock volatility against components of trading activity by type of investor

\begin{tabular}{|c|c|c|c|c|c|c|c|}
\hline & (1) & (2) & (3) & (4) & (5) & (6) & (7) \\
\hline Dependent variable: $\ln \left(\sigma_{i t}\right)$ & Total Sample & $2007-2011$ & 2012-2016 & Quartile 1 & Quartile 2 & Quartile 3 & Quartile 4 \\
\hline $\ln \left(\sigma_{\text {colcap }, t}\right)$ & $0,3818 * * *$ & $0,4158 * * *$ & $0,3457 * * *$ & $0,3457 * * *$ & $0,3566^{* * *}$ & $0,4226 * * *$ & $0,4703 * * *$ \\
\hline $\ln \left(\sigma_{u s d c o p, t}\right)$ & $0,1094 * * *$ & $0,0412 * * *$ & $0,1663 * * *$ & $0,1663 * * *$ & $0,1040 * * *$ & $0,0843 * * *$ & $0,0958 * * *$ \\
\hline$r_{i, t}$ & $0,1135^{* *}$ & $1,0110 * *$ & 0,051 & 0,051 & 0,1738 & $-0,1955$ & $-0,2196$ \\
\hline$r_{i, t-1}$ & $-0,4700 *$ & 0,3623 & $-1,2221 * * *$ & $-1,2221 * * *$ & $-0,4208$ & $-0,9016^{*}$ & $-0,4363$ \\
\hline $\ln \left(1+N_{-}\right.$trades_ext $\left.{ }_{i, t}\right)$ & $0,0898 * * *$ & $0,0304 * * *$ & $0,0894 * * *$ & $0,0894 * * *$ & $0,1208 * * *$ & $0,1085 * * *$ & $0,0334 * * *$ \\
\hline $\ln \left(1+N_{-}\right.$trades_inst $\left.{ }_{i, t}\right)$ & $0,1027 * * *$ & $0,0723 * * *$ & $0,1242 * * *$ & $0,1242^{* * *}$ & $0,1278 * * *$ & $0,0931 * * *$ & $0,1241^{* * *}$ \\
\hline $\ln \left(1+N \_t r a d e s_{-}\right.$indiv $\left._{i, t}\right)$ & $0,1870 * * *$ & $0,2454 * * *$ & $0,1900 * * *$ & $0,1900 * * *$ & $0,1750 * * *$ & $0,1400 * * *$ & $0,0786^{* * *}$ \\
\hline $\ln \left(1+\right.$ avg_traded_value_ext $\left.t_{i, t}\right)$ & $-0,0069 * * *$ & $-0,0031 * * *$ & $-0,0043 * * *$ & $-0,0043 * * *$ & $-0,0140 * * *$ & $-0,0081 * * *$ & $-0,0003$ \\
\hline $\ln \left(1+\right.$ avg_traded_value_inst $\left.t_{i, t}\right)$ & $-0,0049$ & 0,0052 & $-0,0234 * * *$ & $-0,0234 * * *$ & $-0,0219 * * *$ & $-0,0044$ & $-0,0052$ \\
\hline $\ln \left(1+\right.$ avg_traded_value_indiv $\left.v_{i, t}\right)$ & $-0,0072$ & $-0,0105$ & 0,0007 & 0,0007 & $0,0741 * * *$ & $-0,0205 * * *$ & 0,0211 \\
\hline Constant & $-2,9432 * * *$ & $-3,3043 * * *$ & $-2,7949 * * *$ & $-2,7949 * * *$ & $-4,2614^{* * *}$ & $-2,4373 * * *$ & $-2,8462 * * *$ \\
\hline $\mathrm{N}$ & 36.820 & 17.401 & 19.419 & 19.419 & 7.540 & 13.084 & 9.338 \\
\hline R-squared & 0,251 & 0,273 & 0,261 & 0,261 & 0,242 & 0,253 & 0,247 \\
\hline Number of stocks & 37 & 29 & 30 & 30 & 7 & 10 & 9 \\
\hline \multicolumn{8}{|l|}{ Wald Test } \\
\hline$N_{-} o p_{-} e x t_{i, t}=N_{-} o p_{-}$inst $t_{i, t}$ & 2,48 & $13,33 * * *$ & $9,723 * * *$ & $9,72 * * *$ & 0,14 & 1,15 & $28,89 * * *$ \\
\hline$N_{-} o_{-}$inst $_{i, t}=N_{-} o_{-} \_$indiv $v_{i, t}$ & $54,35 * * *$ & $101,8^{* * *}$ & $15,99 * * *$ & $79,39 * * *$ & $3,24 *$ & $7,31 * *$ & $3,88^{* *}$ \\
\hline$N_{-} o p_{-} e x t_{i, t}=N_{-} o p_{-} i n d i v_{i, t}$ & $202,4 * * *$ & $304,1 * * *$ & $79,39 * * *$ & $15,99 * * *$ & $14,08 * * *$ & $5,58^{* *}$ & $13,21 * * *$ \\
\hline 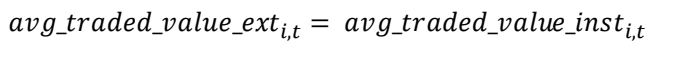 & 0,317 & $5,064 * *$ & $6,232 * *$ & $6,23 * *$ & 1,09 & 0,12 & 0,31 \\
\hline avg_traded_value_inst $_{i, t}={\text { avg_traded_value_indiv } v_{i, t}}$ & 0,104 & 0,584 & $5,100 * *$ & $5,10 * *$ & $23,49 * * *$ & 1,20 & 1,91 \\
\hline avg_traded_value_ext ${ }_{i, t}=$ avg_traded_value_indiv $v_{i, t}$ & 0,0025 & 2,085 & 0,594 & 0,59 & $27,21 * * *$ & 2,40 & 2,41 \\
\hline
\end{tabular}

This table reports the results of the panel data models regressing the stock price volatility $\ln \left(\sigma_{i t}\right)$ against the average traded value and number of trades by type of investor, at daily frequency, as in [2]. Column (1) presents the results for the total sample from January 1 , 2007 to January 29, 2016. Columns (2) and (3) present the corresponding results for the two half-periods. Columns (4) to (7) show the estimations for the four size quartiles. Wald tests are reported comparing the coefficients for both number of trades and average traded value among the three types of traders. The panel data models are estimated with fixed effects and the Driscoll \& Kraay (1998) covariance matrix estimator. The data comes from the Colombia Stock Exchange (BVC) and Bloomberg. N: Number of stock-days. *,**,***: Statistical significance at the $10 \%, 5 \%$ and $1 \%$ levels, respectively. 
Table 5. Regressing stock volatility against buying and selling activity by type of investor

\begin{tabular}{|c|c|c|c|c|c|c|c|}
\hline Dependent variable: $\ln \left(\sigma_{i t}\right)$ & $\begin{array}{c}(1) \\
\text { Total Sample } \\
\end{array}$ & $\begin{array}{c}(2) \\
2007-2011 \\
\end{array}$ & $\begin{array}{c}(3) \\
2012-2016 \\
\end{array}$ & $\begin{array}{c}\text { (4) } \\
\text { Quartile 1 } \\
\end{array}$ & $\begin{array}{c}\text { (4) } \\
\text { Quartile 2 } \\
\end{array}$ & $\begin{array}{c}\text { (4) } \\
\text { Quartile } 3 \\
\end{array}$ & $\begin{array}{c}\text { (4) } \\
\text { Quartile } 4 \\
\end{array}$ \\
\hline $\ln \left(\sigma_{\text {colcap }, t}\right)$ & $0,4171 * * *$ & $0,4479 * * *$ & $0,3879 * * *$ & $0,2910 * * *$ & $0,3749 * * *$ & $0,4606 * * *$ & $0,4949 * * *$ \\
\hline $\ln \left(\sigma_{u s d c o p, t}\right)$ & $0,1043 * * *$ & $0,0410 * * *$ & $0,1595 * * *$ & $0,1694 * * *$ & $0,1083 * * *$ & $0,0740 * * *$ & $0,0880 * * *$ \\
\hline$r_{i, t}$ & $0,2030^{* * *}$ & $1,5312^{* * *}$ & $0,1069^{*}$ & $0,1822^{* * *}$ & 0,5315 & 0,1189 & 0,2628 \\
\hline$r_{i, t-1}$ & $-0,2821$ & 0,6341 & $-1,1042 * * *$ & 0,2505 & $-0,2823$ & $-0,9652 *$ & $-0,297$ \\
\hline $\ln \left(1+\right.$ traded_value_buy_ext $\left.t_{i, t}\right)$ & $0,0052 * * *$ & 0,0008 & $0,0079 * * *$ & $0,0039 * * *$ & $0,0048 * * *$ & $0,0076^{* * *}$ & $0,0025^{* *}$ \\
\hline $\ln \left(1+\right.$ traded_value_buy_inst $\left.{ }_{i, t}\right)$ & $0,0120^{* * *}$ & $0,0079 * * *$ & $0,0266^{* * *}$ & $0,0109 * * *$ & $0,0097 * * *$ & $0,0118^{* * *}$ & $0,0107 * * *$ \\
\hline $\ln \left(1+\right.$ traded_value_buy_indiv $\left.v_{i, t}\right)$ & $0,0294 * * *$ & $0,0288 * * *$ & $0,0291 * * *$ & $0,0294 * * *$ & $0,0447 * * *$ & $0,0254 * * *$ & $0,0210^{* * *}$ \\
\hline $\ln \left(1+\right.$ traded_value_sell_ext $\left.t_{i, t}\right)$ & $0,0072 * * *$ & $0,0043 * * *$ & $0,0071 * * *$ & $0,0077 * * *$ & $0,0055 * * *$ & $0,0079 * * *$ & $0,0060 * * *$ \\
\hline $\ln \left(1+\right.$ traded_value_sell_inst $\left.{ }_{i, t}\right)$ & $0,0163 * * *$ & $0,0147 * * *$ & $0,0170 * * *$ & $0,0166^{* * *}$ & $0,0133 * * *$ & $0,0183 * * *$ & $0,0131 * * *$ \\
\hline $\ln \left(1+\right.$ traded_value_sell_indiv $\left.{ }_{i, t}\right)$ & $0,0389 * * *$ & $0,0696 * * *$ & $0,0340 * * *$ & $0,0734 * * *$ & $0,0749 * * *$ & $0,0232 * * *$ & $0,0241 * * *$ \\
\hline Constant & $-3,8346^{* * *}$ & $-4,4268 * * *$ & $-3,9648 * * *$ & $-4,4146^{* * *}$ & $-4,9893 * * *$ & $-3,4814^{* * *}$ & $-3,0956^{* * *}$ \\
\hline $\mathrm{N}$ & 36.820 & 17.401 & 19.419 & 6.858 & 7.540 & 13.084 & 9.338 \\
\hline R-squared & 0,210 & 0,235 & 0,213 & 0,222 & 0,212 & 0,214 & 0,230 \\
\hline Number of stocks & 37 & 29 & 30 & 11 & 7 & 10 & 9 \\
\hline \multicolumn{8}{|l|}{ Wald Test } \\
\hline traded_value_buy_ext $t_{i, t}=$ traded_value_buy_inst $_{i, t}$ & $17,35^{* * *}$ & $14,61 * * *$ & $27,11 * * *$ & $8,36 * *$ & 1,61 & 1,23 & $4,71 * *$ \\
\hline traded_value_buy_inst $t_{i, t}=$ traded_value_buy_indiv ${ }_{i, t}$ & $56,90 * * *$ & $36,61 * * *$ & 0,39 & $22,50 * * *$ & $33,31 * * *$ & $7,20 * *$ & $4,24 * *$ \\
\hline traded_value_buy_ext $t_{i, t}=$ traded_value_buy_indiv $v_{i, t}$ & $188,08 * * *$ & $77,92 * * *$ & $88,96 * * *$ & $56,33 * * *$ & $67,59 * * *$ & $35,50 * * *$ & $28,86^{* * *}$ \\
\hline traded_value_sell_ext $t_{i, t}=$ traded_value_sell_inst $t_{i, t}$ & $39,99 * * *$ & $39,95 * * *$ & $11,83 * * *$ & $15,24 * * *$ & $7,62 * *$ & $9,95 * * *$ & $3,63 * *$ \\
\hline traded_value_sell_inst $t_{i, t}=$ traded_value_sell_indiv $v_{i, t}$ & $52,73 * * *$ & $59,19 * * *$ & $14,97^{* * *}$ & $52,24 * * *$ & $41,27 * * *$ & 0,85 & 2,35 \\
\hline${ }_{\text {traded_value_sell_ext }}{ }_{i, t}=$ traded_value_sell_indiv $v_{i, t}$ & $129,35^{* * *}$ & $87,75^{* * *}$ & $67,83 * * *$ & $75,51 * * *$ & $60,75^{* * *}$ & $14,38 * * *$ & $9,93 * * *$ \\
\hline
\end{tabular}

This table reports the results of the panel data models regressing the stock price volatility $\ln \left(\sigma_{i t}\right)$ against traded value in both buys and sells by type of investor, at daily frequency, as in [2]. Column (1) presents the results for the total sample from January 1, 2007 to January 29, 2016. Columns (2) and (3) present the corresponding results for the two half-periods. Columns (4) to (7) show the estimations for the four size quartiles. Wald tests that compare the three buying and three selling coefficients are reported. The panel data models are estimated with fixed effects and the Driscoll \& Kraay (1998) covariance matrix estimator. The data come from the Colombia Stock Exchange (BVC) and Bloomberg. N: Number of stock-days. *, **, ***: Statistical significance at the 10\%, 5\% and 1\% levels, respectively. 
Table 6. Effects of trading by type of investor on intraday measures of volatility and liquidity

(1)

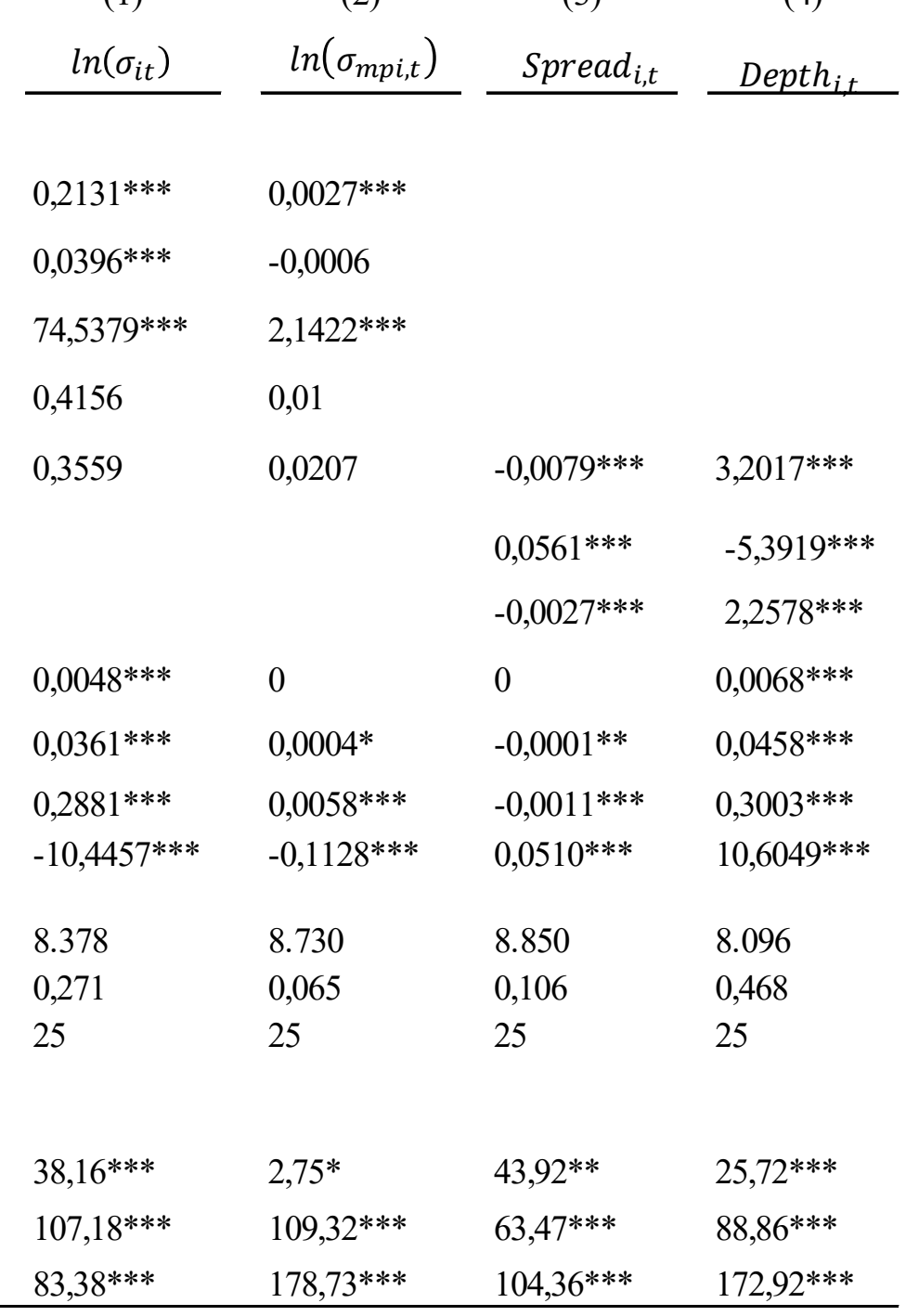

(2)

(3)
Dependent variable:

$\ln \left(\sigma_{\text {colcap }, t}\right)$

$\ln \left(\sigma_{\text {usdcop }, t}\right)$

instrument_spread $_{i, t}$

$r_{i, t-1}$

$r_{i, t}$

instrument_volatility $_{i, t}$

$\log _{-}$price $-i, t$

$\ln \left(1+\right.$ traded_value_ext $\left.{ }_{i, t}\right)$

$\ln \left(1+\right.$ traded_value_inst $\left._{i, t}\right)$

$\ln \left(1+\right.$ traded_value_indiv $\left._{i, t}\right)$

Constant

$\mathrm{N}$

R-squared

Number of stocks

Wald Test

traded_value_ext ${ }_{i, t}=$ traded_value_inst $_{i, t}$

traded_value_inst $t_{i, t}=$ traded_value_indiv $v_{i, t}$

traded_value_ext $t_{i, t}=$ traded_value_indiv $_{i, t}$

This table reports the results of the panel data models regressing the measures of volatility and liquidity at the stock-day level against the trading value by type of investor and control variables. Column (1) presents the results for the model of stock price volatility [2], Column (2) the midprice volatility [3], Column (3) the effective spread [6], and Column (4) the average depth [7]. Wald tests that compare the three trading activity coefficients are reported. All models are estimated with the two-stage least squares method to account for the endogeneity between liquidity and volatility, fixed effects, and the Driscoll \& Kraay (1998) covariance matrix estimator. The data come from the Colombia Stock Exchange (BVC) and Bloomberg from August 23, 1010 to August 31,2012 . N: Number of stock-days. *, **, ***: Statistical significance at the $10 \%, 5 \%$ and $1 \%$ levels, respectively. 


\section{Table 7. Effects on intraday measures of volatility and liquidity, decomposing trading activity}

(1)
Dependent variable:

$\ln \left(\sigma_{\text {colcap }, t}\right)$

$\ln \left(\sigma_{\text {usdcop }, t}\right)$

instrument_spread $_{i, t}$

$r_{i, t-1}$

$r_{i, t}$

instrument_volatility $_{i, t}$

$\log _{-}$price $_{-i, t}$

$\ln \left(1+N_{-}\right.$trades_ext $\left.{ }_{i, t}\right)$

$\ln \left(1+N_{-}\right.$trades_inst $\left._{i, t}\right)$

$\ln \left(1+N_{-}\right.$trades_indiv $\left.v_{i, t}\right)$

$\ln \left(1+\right.$ avg_traded_value_ext $\left.t_{i, t}\right)$

$\ln \left(1+\right.$ avg_traded_value_inst $\left.t_{i, t}\right)$

$\ln \left(1+\right.$ avg_traded_value_indiv $\left.v_{i, t}\right)$

Constant

$\mathrm{N}$

$\mathrm{R}$-squared

Number of stocks

Wald Test

$N_{-}$trades_ext $t_{i, t}=N_{-}$trades_inst $t_{i, t}$

$N_{-}$trades_inst $_{i, t}=N_{-}$trades_indiv ${ }_{i, t}$

$N_{-}$trades_ext $t_{i, t}=N_{-}$trades_indiv ${ }_{i, t}$

avg_traded_value_ext $t_{i, t}=$ avg_traded_value_inst $t_{i, t}$

$a v g_{-} t r a d e d \_v a l u e_{-} i n s t_{i, t}=a v g_{-} t r a d e d \_v a l u e_{-} i n d i v v_{i, t}$

$a v g \_t r a d e d \_v a l u e_{-} e x t_{i, t}=a v g_{-} t r a d e d \_v a l u e_{-} i n d i v_{i, t}$

\begin{tabular}{|c|c|c|c|}
\hline $\ln \left(\sigma_{i t}\right)$ & $\ln \left(\sigma_{m p i, t}\right)$ & Spread $_{i, t}$ & Depth $_{i, t}$ \\
\hline $0,1908^{* * *}$ & $0,0021 * * *$ & & \\
\hline $0,0407 * * *$ & $-0,0005$ & & \\
\hline $74,7274 * * *$ & $2,2019 * * *$ & & \\
\hline 0,3047 & 0,0068 & & \\
\hline \multirow[t]{3}{*}{0,0244} & 0,0132 & $-0,0076^{* *}$ & $2,8109 * * *$ \\
\hline & & $0,0585^{* * *}$ & $-5,062 * * *$ \\
\hline & & $-0,0028 * * *$ & $2,0731 * * *$ \\
\hline $0,0580^{* * *}$ & 0,0003 & 0,0001 & $0,0434 * * *$ \\
\hline $0,1268 * * *$ & $0,0031 * * *$ & $-0,0004 * * *$ & $0,2364 * * *$ \\
\hline $0,3053^{* * *}$ & $0,0069 * * *$ & $-0,0012 * * *$ & $0,0706^{* * *}$ \\
\hline$-0,0040 * *$ & $-0,0001$ & 0 & 0,0015 \\
\hline 0,0071 & $-0,0003$ & 0 & 0,0024 \\
\hline $0,1396^{* * *}$ & $0,0015^{* * *}$ & $-0,0003^{* *}$ & $0,5115^{* * *}$ \\
\hline$-7,9442 * * *$ & $-0,0438^{* * *}$ & $0,0446 * * *$ & $9,4793 * * *$ \\
\hline 8.378 & 8.730 & 8.850 & 8.096 \\
\hline 0,297 & 0,079 & 0,109 & 0,500 \\
\hline 25 & 25 & 25 & 25 \\
\hline
\end{tabular}

$19,57 * * * \quad 22,10^{* *} \quad 12,30^{* * *} \quad 56,48^{* * *}$

$54,94 * * * \quad 19,58 * * * \quad 12,53 * * * \quad 20,28 * * *$

$223,92 * * * \quad 99,71 * * * \quad 55,05 * * * \quad 1,06$

$3,43 * * \quad 0,84 \quad 0,02 \quad 0,01$

$53,05^{* * *} \quad 12,58^{* * *} \quad 6,56^{* *} \quad 41,82^{* * *}$

$78,47 * * * \quad 13,53 * * * \quad 5,63 * * \quad 44,81 * * *$

This table reports the results of the panel data models regressing the measures of volatility and liquidity at the stock-day level against the average traded value and number of trades by type of investor and control variables. Column (1) presents the results for the model of stock price volatility [2], Column (2) the mid-price volatility [3], Column (3) the effective spread [6], and Column (4) the average depth [7]. Wald tests that compare the three coefficients for the number of trades and the three coefficients for the average traded value are reported. All models are estimated with the two-stage least squares method to account for the endogeneity between liquidity and volatility, fixed effects, and the Driscoll \& Kraay (1998) covariance matrix estimator. The data come from the Colombia Stock Exchange (BVC) and Bloomberg from August 23, 2010 to August 31, 2012. $\mathrm{N}$ : Number of stock-days. *,**,***: Statistical significance at the $10 \%, 5 \%$ and $1 \%$ levels, respectively. 
Table 8. Regressing intraday volatility estimators against components of trading activity by type of investor

(1)

\begin{tabular}{|c|c|c|c|}
\hline $\begin{array}{c}(1) \\
\ln \left(\sigma_{m p i, t}\right) \\
\end{array}$ & $\begin{array}{c}(2) \\
\ln \left(B V_{i, t}\right) \\
\end{array}$ & $\begin{array}{c}(3) \\
\ln \left(T S R V_{i, t}\right) \\
\end{array}$ & $\begin{array}{c}(4) \\
\ln \left(M e d R V_{i, t}\right)\end{array}$ \\
\hline $0,0027 * * *$ & $0,0015^{* * *}$ & $0,0021 * * *$ & 0,0830 \\
\hline$-0,0006$ & $0,0005^{* *}$ & $-0,0002$ & 0,02269 \\
\hline $2,1422 * * *$ & $0,8980^{* * * *}$ & $0,9058 * * *$ & $77,3980 * * *$ \\
\hline 0,01 & 0,0078 & $0,027 * *$ & $-0,7381$ \\
\hline 0,0207 & $-0,0089$ & $-0,1637 * * *$ & $-3,1947$ \\
\hline 0 & $0,0000^{* * *}$ & $0,0001^{* * *}$ & $0,0059^{* *}$ \\
\hline $0,0004 *$ & $0,0006^{* * *}$ & $0,0004 * * *$ & $0,0130 * *$ \\
\hline $0,0058^{* * *}$ & $0,0033^{* * *}$ & $0,0037 * * *$ & $0,1377 * * *$ \\
\hline$-0,1128 * * *$ & $-0,0678^{* * *}$ & $0,0687^{* * *}$ & $-2,4254 * *$ \\
\hline 8.730 & 7.715 & 4.786 & 7.773 \\
\hline 0,065 & 0,219 & 0,259 & 0,059 \\
\hline 25 & 23 & 23 & 23 \\
\hline $38,16^{* * *}$ & $45,99 * * *$ & $11,50^{* *}$ & 0,93 \\
\hline $107,18^{* * *}$ & $137,08 * * *$ & $99,97 * * *$ & $6,13 * * *$ \\
\hline $83,38 * * *$ & 253,80 *** & $169,42 * * *$ & $7,56 * * *$ \\
\hline
\end{tabular}

(2)

(3)

(4)
Dependent variable:

$\ln \left(\sigma_{\text {colcap }, t}\right)$

$\ln \left(\sigma_{\text {usdcop }, t}\right)$

instrument_spread $_{i, t}$

$r_{i, t-1}$

$r_{i, t}$

$\ln \left(1+\right.$ traded_value_ext $\left._{i, t}\right)$

$\ln \left(1+\right.$ traded_value_inst $\left._{i, t}\right)$

$\ln \left(1+\right.$ traded_value_indiv $\left._{i, t}\right)$

Constant

$\mathrm{N}$

R-squared

Number of stocks

\section{Wald Test}

traded_value_ext $t_{i, t}=$ traded_value_inst $t_{i, t}$

traded_value_inst $_{i, t}=$ traded_value_indiv $v_{i, t}$

traded_value_ext $t_{i, t}=$ traded_value_indiv $v_{i, t}$

This table reports the results of the panel data models regressing alternative intraday measures of volatility against the average traded value and number of trades by type of investor and control variables at the stock-day level. Column (1) presents the results for the model of stock price volatility [2], Column (2) the bipower variation measure [8], Column (3) the TSRV estimation [9], and Column (4) the median realized volatility [12]. Wald tests that compare the three trading activity coefficients are reported. All models are estimated with the two-stage least squares method to account for the endogeneity between liquidity and volatility, fixed effects, and the Driscoll \& Kraay (1998) covariance matrix estimator. The data come from the Colombia Stock Exchange (BVC) and Bloomberg from August 23, 1010 to August 31, 2012. N: Number of stock-days. *, **, ***: Statistical significance at the $10 \%, 5 \%$ and $1 \%$ levels, respectively. 
Table 9. Average trading cost for buys and sells by type of investor

\begin{tabular}{|c|c|c|c|c|c|c|c|c|c|c|c|c|c|c|}
\hline \multirow[b]{3}{*}{ Quartile } & \multicolumn{4}{|c|}{ Foreigners } & \multicolumn{4}{|c|}{ Local Institutions } & \multicolumn{6}{|c|}{ Local Individuals } \\
\hline & \multicolumn{2}{|r|}{ Buys } & \multicolumn{2}{|r|}{ Sells } & \multicolumn{2}{|r|}{ Buys } & \multicolumn{2}{|r|}{ Sells } & \multicolumn{3}{|c|}{ Buys } & \multicolumn{3}{|c|}{ Sells } \\
\hline & $\mathrm{N}$ & Mean & $\mathrm{N}$ & Mean & $\mathrm{N}$ & Mean & $\mathrm{N}$ & Mean & $\mathrm{N}$ & Mean & $\begin{array}{c}\mathrm{t} \text {-test }> \\
\text { Institutions }\end{array}$ & $\mathrm{N}$ & Mean & $\begin{array}{c}\mathrm{t} \text {-test }> \\
\text { Institutions }\end{array}$ \\
\hline Total & 7.093 & $0,10 \% * * *$ & 5.827 & $0,07 \% * * *$ & 9.543 & $-0,01 \% * *$ & 9.470 & $-0,04 \% * * *$ & 9.777 & $-0,10 \% * * *$ & $-15,3 * * *$ & 9.844 & $-0,03 \% * * *$ & 1,8 \\
\hline 4 & 1.723 & $0,07 \% * * *$ & 1.456 & $0,06 \% * * *$ & 1.915 & $-0,02 \% * * *$ & 1.908 & $-0,02 \% *$ & 1.930 & $-0,08 \% * * *$ & $-7,2 * * *$ & 1.932 & $-0,03 \% * * *$ & $-0,7$ \\
\hline 3 & 2.666 & $0,10 \% * * *$ & 2.193 & $0,07 \% * * *$ & 3.023 & $-0,03 \% * * *$ & 3.021 & $-0,04 \% * * *$ & 3.027 & $-0,12 \% * * *$ & $-10,4 * * *$ & 3.051 & $-0,03 \% * * *$ & 0,6 \\
\hline 2 & 1.493 & $0,11 \% * * *$ & 1.135 & $0,07 \% * * *$ & 2.205 & $0,00 \%$ & 2.181 & $-0,04 \% * *$ & 2.280 & $-0,08 \% * * *$ & $-7,6 * * *$ & 2.284 & $0,00 \%$ & $4,4 * * *$ \\
\hline 1 & 1.211 & $0,15 \% * * *$ & 1.043 & $0,10 \% * * *$ & 2.400 & $0,02 \%$ & 2.360 & $-0,04 \% *$ & 2.540 & $-0,09 \% * * *$ & $-7,0 * * *$ & 2.577 & $-0,05 \% * * *$ & $-0,4$ \\
\hline
\end{tabular}

This table reports the summary statistics of the average trading cost at stock-day level (equations [13] and [14]) in both buys and sells for the three types of investors, for the overall market and for the four size quartiles. The data come from the Colombia Stock Exchange (BVC), from August 23, 1010 to August 31, 2012. Two-tailed t-statistics for the mean differences between groups are provided. N: Number of stock-days. N: Number of stock-days. *, **, ***: Statistical significance at the $10 \%, 5 \%$ and $1 \%$ levels, respectively.

Table 10. Daily Performance Measure by type of investor

\begin{tabular}{rrccc} 
& & Foreigners & Local Institutions & Local Individuals \\
\cline { 3 - 5 } Quartile & $\mathrm{N}$ & Mean & Mean & Mean \\
\hline Total & 9.668 & $0,02 \%$ & $0,07 \% * * *$ & $-0,11 \% * * *$ \\
4 & 1.922 & $0,03 \%$ & $0,02 \%$ & $-0,07 \% * *$ \\
3 & 3.050 & $0,04 \% *$ & $0,06 \% * *$ & $-0,13 \% * * *$ \\
2 & 2.222 & $0,00 \%$ & $0,06 \% *$ & $-0,09 \% * *$ \\
1 & 2.474 & $0,01 \%$ & $0,12 \% * * *$ & $-0,14 \% * * *$
\end{tabular}

This table reports the summary statistics of the daily performance measures [15] for the three types of investors, for the overall market and for the four size quartiles. The data come from the Colombia Stock Exchange (BVC), from August 23, 1010 to August $31,2012$. Two-tailed t-statistics for the mean differences between groups are provided. N: Number of stock-days. N: Number of stock-days. *, **, ***: Statistical significance at the $10 \%, 5 \%$ and $1 \%$ levels, respectively. 
Table 11. Regressing stock volatility against total traded value by investor in times of financial stress

\begin{tabular}{|c|c|c|c|c|c|c|c|}
\hline \multirow{3}{*}{$\begin{array}{l}\ln \left(\sigma_{\text {colcap }, t}\right) \\
\ln \left(\sigma_{\text {usdcop }, t}\right)\end{array}$} & $\begin{array}{c}\text { (1) } \\
\text { Basic Model }\end{array}$ & \multicolumn{2}{|c|}{$\begin{array}{l}\text { (2) } \\
\text { Restricted to Days }\end{array}$} & \multicolumn{2}{|c|}{$\begin{array}{l}\text { (4) } \\
\text { Restricted to Days } \\
\Delta V I X>p 90\end{array}$} & \multicolumn{2}{|c|}{$\begin{array}{c}\text { (6) }(7) \\
\text { Interactions with dummy } \\
\text { of High VIX }\end{array}$} \\
\hline & $0,4148^{* * *}$ & $0,4687^{* * *}$ & & $0,4376^{* * *}$ & & $0,4120^{* * *}$ & \\
\hline & $0,1053^{* * *}$ & $0,0286^{* *}$ & & $0,0679 * * *$ & & $0,1057^{* * *}$ & \\
\hline$r_{i, t}$ & $0,1894 * * *$ & 0,663 & $-2,3489 * *$ & 0,0321 & $-4,6316^{* * *}$ & $0,1882^{* * *}$ & 0,0244 \\
\hline$r_{i, t-1}$ & $-0,4122$ & $-0,1037$ & $-3,0266^{* * *}$ & $-2,2335^{* * *}$ & $-3,3833 * * *$ & $-0,4367$ & $-1,2956^{* * *}$ \\
\hline $\ln \left(1+\right.$ traded_value_ext $\left.t_{i, t}\right)$ & $0,0082^{* * *}$ & $0,0047^{* * *}$ & $0,0046^{* *}$ & $0,0066^{* * *}$ & $0,0072 * * *$ & $0,0094^{* * *}$ & $0,0079 * * *$ \\
\hline $\ln \left(1+\right.$ traded_value_inst $\left._{i, t}\right)$ & $0,0276^{* * *}$ & $0,0168^{* * *}$ & $0,0179 * * *$ & $0,0256^{* * *}$ & $0,0245^{* * *}$ & $0,0326^{* * *}$ & $0,0297 * * *$ \\
\hline $\ln \left(1+\right.$ traded_value_indiv $\left.v_{i, t}\right)$ & $0,1097^{* * *}$ & $0,1127^{* * *}$ & $0,1597 * * *$ & $0,1259 * * *$ & $0,1627^{* * *}$ & $0,1115^{* * *}$ & $0,1325^{* * *}$ \\
\hline $\ln \left(1+\right.$ traded_value_ext $\left._{i, t}\right) \times d_{-}$high_VIX & & & & & & $-0,0053^{* * *}$ & $-0,0046^{* * *}$ \\
\hline $\ln \left(1+\right.$ traded_value_inst $\left._{i, t}\right) \times d_{-}$high_VIX & & & & & & $-0,0177^{* * *}$ & $-0,0173^{* * *}$ \\
\hline $\ln \left(1+\right.$ traded_value_indiv $\left.v_{i, t}\right) \times d_{-}$high_VIX & & & & & & $-0,0141$ & $-0,0002$ \\
\hline d_high_vix & & & & & & $0,7672 * * *$ & $0,5519 * *$ \\
\hline Constant & $-4,7739 * * *$ & $-4,6492 * * *$ & $-7,8504 * * *$ & $-5,1265^{* * *}$ & $-8,1405 * * *$ & $-4,9550 * * *$ & $-7,7293 * * *$ \\
\hline $\begin{array}{l}\mathrm{N} \\
\mathrm{R} \text {-squared } \\
\text { Number of stocks }\end{array}$ & $\begin{array}{l}36.820 \\
0,205 \\
37\end{array}$ & $\begin{array}{l}4.613 \\
0,264 \\
36 \\
\end{array}$ & $\begin{array}{l}4.709 \\
0,108 \\
36 \\
\end{array}$ & $\begin{array}{l}5.307 \\
0,268 \\
37 \\
\end{array}$ & $\begin{array}{l}5.909 \\
0,136 \\
37 \\
\end{array}$ & $\begin{array}{l}36.820 \\
0,207 \\
37 \\
\end{array}$ & $\begin{array}{l}40.800 \\
0,095 \\
37 \\
\end{array}$ \\
\hline
\end{tabular}

This table reports the results of the panel data models regressing the stock price volatility $\ln \left(\sigma_{i t}\right)$ against the traded value by type of investor at daily frequency, as in [2], exploring the effects of trading on days of financial stress. Column (1) presents the results for the total sample from January 1, 2007 to January 29, 2016. Columns (2) and (3) show the results of the model restricted to days with high VIX values (above 90th percentile $=32,85$ ), and Columns (4) and (5) present the results restricted to the days with large daily changes in the VIX (above 90th percentile=1,85). Columns (6) and (7) show the results for the whole sample but include the dummy variable $d_{-}$high_vix for high VIX values $(>32,85)$ and its interactions with the three trading activity variables. Volatilities are measured as $\sigma_{t}=$ $\ln \left(\right.$ High_price $\left._{t}\right)-\ln \left(\right.$ Low_price $\left._{t}\right)$ where High_price ${ }_{t}\left(\right.$ Low_price $\left._{t}\right)$ is the respective maximum (minimum) price. Panel data models are estimated with fixed effects and the Driscoll \& Kraay (1998) covariance matrix estimator. The data come from the Colombia Stock Exchange (BVC) and Bloomberg. N: Number of stock-days. *, **, ***: Statistical significance at the 10\%, 5\% and 1\% levels, respectively. 


\section{Table 12. Effects on microstructural components of volatility (Short-term and long-term local institutions)}

(1)

Dependent variable:

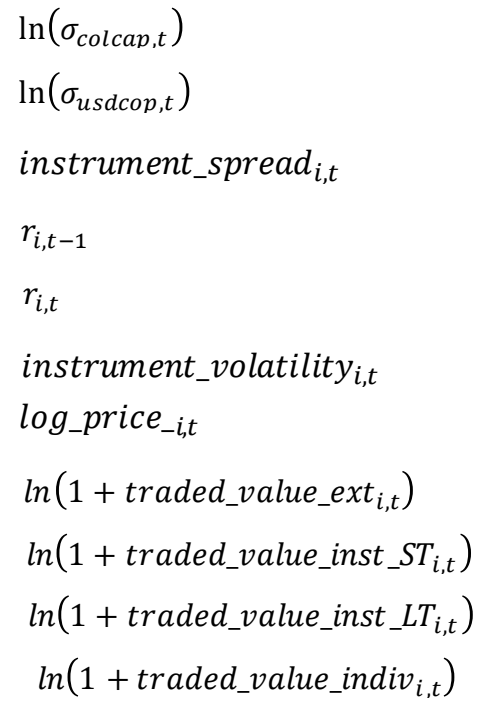

Wald Test

\begin{tabular}{|c|c|c|c|c|}
\hline traded_value_ext $_{i, t}=$ traded_value_inst_ST $T_{i, t}$ & $23,99 * * *$ & $4,35^{* *}$ & $4,43^{* *}$ & $12,42 * * *$ \\
\hline traded_value_ext ${ }_{i, t}=$ traded_value_inst_LT $T_{i, t}$ & $9,67^{* * *}$ & 2,04 & $3,55^{*}$ & 0,16 \\
\hline raded_value_inst_S$S T_{i, t}=$ traded_value_inst_L$L T_{i, t}$ & $10,33 * * *$ & 1,30 & 1,49 & $9,78^{* * *}$ \\
\hline aded_value_indiv $v_{i, t}=$ traded_value_inst_ST$T_{i, t}$ & $618,94^{* * *}$ & $146,37 * * *$ & $64,25 * * *$ & $134,75^{* * *}$ \\
\hline aded_value_indiv $v_{i, t}=$ traded_value_inst_LT$T_{i, t}$ & $792,88 * *$ & $175,49 * * *$ & $85,17 * * *$ & $177,20 * * *$ \\
\hline
\end{tabular}

This table reports the results of the panel data models regressing the measures of volatility and liquidity at the stock-day level against the trading value by four types of investors: foreigners, local individuals, and local short-term and long-term institutions. Column (1) presents the results for the model of stock price volatility [2], Column (2) the mid-price volatility [3], Column (3) the effective spread [6], and Column (4) the average depth [7]. Wald tests that compare the trading activity coefficients of the different groups are reported. All models are estimated with the two-stage least squares method to account for the endogeneity between liquidity and volatility, fixed effects, and the Driscoll \& Kraay (1998) covariance matrix estimator. The data come from the Colombia Stock Exchange (BVC) and Bloomberg from August 23, 1010 to August 31, 2012. N: Number of stockdays. $* * *, * * *$ : Statistical significance at the $10 \%, 5 \%$ and $1 \%$ levels, respectively. 